\title{
Uranium Transport in a Crushed Granodiorite: Experiments and Reactive Transport Modeling
}

\author{
T.M. Dittrich ${ }^{\mathrm{a}, *}$ and P.W. Reimus ${ }^{\mathrm{a}}$ \\ ${ }^{a}$ Earth and Environmental Sciences Division, Los Alamos National Laboratory, Los Alamos, NM 87545, USA \\ * Corresponding author: Los Alamos National Laboratory, P.O. Box 1663, Mail Stop J966, Los Alamos, NM 87545 \\ Tel: +1-505-665-2100,Fax: +1-505-606-2258. E-mail address: timdittrich@lanl.gov
}




\begin{abstract}
The primary objective of this study was to develop and demonstrate an experimental method to refine and better parameterize process models for reactive contaminant transport in aqueous subsurface environments and to reduce conservatism in such models without attempting to fully describe the geochemical system. Uranium was used as an example of a moderately adsorbing contaminant because of its relevance in geologic disposal of spent nuclear fuel. A fractured granodiorite from the Grimsel Test Site (GTS) in Switzerland was selected because this system has been studied extensively and field experiments have been conducted with radionuclides including uranium. We evaluated the role of $\mathrm{pH}$, porous media size fraction, and flow interruptions on uranium transport. Rock cores drilled from the GTS were shipped to Los Alamos National Laboratory, characterized by x-ray diffraction and optical microscopy, and used in uranium batch sorption and column breakthrough experiments. A synthetic water was prepared that represented the porewater that would be present after groundwater interacts with bentonite backfill material near a nuclear waste package. Uranium was conservatively transported at $\mathrm{pH}$ 8.8. Significant adsorption and subsequent desorption was observed at $\mathrm{pH} \sim 7$, with long desorption tails resulting after switching the column injection solution to uranium-free groundwater. Our experiments were designed to better interrogate this slow desorption behavior. A three-site model predicted sorption rate constants for a $\mathrm{pH} 7.2$ solution with a $75-150 \mu \mathrm{m}$ granodiorite fraction to be $3.5,0.012$, and $0.012 \mathrm{~mL} / \mathrm{g}-\mathrm{h}$ for the forward reactions and 0.49 , 0.0025 , and $0.001 \mathrm{~h}^{-1}$ for the reverse reactions. Surface site densities were $1.3,0.042$, and 0.042 $\mu \mathrm{mol} / \mathrm{g}$ for the first, second, and third sites, respectively. 10-year simulations show that including a slow binding site increases the arrival time of a uranium pulse by $\sim 70 \%$.
\end{abstract}


Keywords: uranium, granodiorite, reactive transport, desorption, column experiments

\section{Introduction}

Geologic disposal of nuclear waste is intended to protect humans and the environment from unacceptable levels of radioactive contamination over very long time periods (anywhere from thousands to millions of years). At contaminated environmental sites, it is necessary to predict the fate and transport of contaminants in groundwater over many decades or even hundreds of years to make informed site management decisions. These long timescales impart considerable uncertainty in risk assessment predictions, which are used as the basis for disposal system designs, contaminated site management decisions, and/or regulatory oversight of both of these.

Because of this uncertainty, there is often a tendency to be very conservative in predictive models (i.e., to make pessimistic assumptions and greatly simplify process descriptions). For models of fate and transport of contaminants in groundwater systems, this practice often results in using a simple, conservatively-estimated partition coefficient $\left(K_{d}\right.$ value, $\left.\mathrm{ml} / \mathrm{g}\right)$ to describe contaminant interactions with geologic media surfaces (Payne et al., 2013; Davis et al., 2005; Morel and Hering, 1993). The opposite extreme is to use a full description of the geochemical system, with all the solid- and solution-phase species and reactions accounted for in a model. An example of the latter is the component additivity (CA) modeling approach, in which contaminant interactions with media surfaces are represented using a weighted average of all the solidsolution reactions in the system (fully described mechanistically) with the abundances of different mineral surfaces in the system being used as weighting factors (Dong and Wan, 2014; Nebelung and Brendler, 2010; Davis et al., 2004; Waite et al., 2000). While in principle this is a 
very robust approach, it is inevitably data limited and requires an expensive and time-consuming characterization effort to succeed. Such expense is not justified for contaminants that interact so weakly with media surfaces that they can be considered nonreactive in risk assessment calculations or for those that interact so strongly that risk assessments are insensitive to the details of their interactions. However, a significant characterization effort may be justified for contaminants that interact just strongly enough to make their risk/dose calculations highly sensitive to the details of their adsorption/desorption interactions. The objective of this study is to demonstrate a practical approach to addressing the characterization of contaminant-media interactions for contaminants that fall into this latter category while avoiding both the excessive conservatism of a simplified approach and the detailed and costly characterization that comes with a full geochemical description of the system.

Uranium is an example of a radionuclide contaminant that has a wide potential range of adsorption behavior to geologic materials and for which subtle differences in its adsorption behavior can make significant differences in its estimated risk contribution for nuclear waste repositories or contaminated sites. It is an element of concern for nuclear waste repository risk assessments because of its large inventory in spent nuclear fuel, its moderate solubility under oxidizing conditions, and the long half-lives of its isotopes. Uranium has a complex geochemistry that results in as much as a two to three order of magnitude range in its effective adsorption partition coefficient over a $\mathrm{pH}$ range from 6.5 to 9, with a strong dependence on carbonate solution concentrations (Vandenhove et al., 2009; Sheppard et al., 2006; Echevarria et al., 2001). At neutral $\mathrm{pH}$, uranium adsorbs relatively strongly to many mineral surfaces. At $\mathrm{pH}$ greater than 8 in natural waters of typical alkalinity, its adsorption decreases significantly because of the tendency for stable neutral and negatively-charged uranyl carbonate (or ternary 
uranyl-Ca/Mg-carbonate) complexes to form and dominate uranium solution speciation. These neutral or negatively-charged complexes resist adsorption onto negatively-charged mineral surfaces.

This complex geochemical behavior of uranium and the wealth of data available on uranium geochemistry have prompted some researchers to invoke detailed geochemical descriptions to predict uranium transport in subsurface environments (Dong and Wan, 2014; Shang et al., 2014, 2011). Recognition of the difficulties in fully characterizing environmental systems has also prompted semi-mechanistic approaches such as the Generalized Composite Surface Complexation Model of Davis and Curtis (2003) and the multi-rate models of Liu et al. $(2009,2008)$. In this paper, we introduce a simplified variation of these approaches and demonstrate an experimental method for parameterizing the modeling approach. We recognize that our method will require refinements and additional data collection to provide a robust predictive capability for a contaminant with complex geochemistry like uranium and may serve as a complementary method to the approaches mentioned above. However, the method (particularly with future refinements that we recommend later) may be directly suitable for contaminants with less complex geochemistry and solution speciation behavior than uranium.

We used a crushed granodiorite from the Grimsel Test Site (GTS) in Switzerland as a model system, which has been used for many years to study nuclear waste disposal concepts and radionuclide transport processes in crystalline rock (Geckeis et al., 2004; Möri et al., 2003). Crystalline rock is being considered as a nuclear waste repository host medium in several countries (Schwartz, 2012; Soler et al., 2011), and it is also being considered for deep borehole nuclear waste disposal (Bates et al., 2014; Driscoll et al., 2012). An attractive feature of the GTS is that it has infrastructure in place to conduct field radionuclide transport experiments, and thus 
it offers the potential to compare radionuclide transport behavior observed at laboratory and field scales. We note here that many deep crystalline rock environments have reducing redox potentials and uranium mobility is known to be much lower in reducing environments than in oxidizing environments because $\mathrm{U}(\mathrm{IV})$ is much less soluble and more adsorptive than $\mathrm{U}(\mathrm{VI})$. In this paper we consider only oxidizing systems in which uranium is likely to remain in the more mobile U(VI) form. The intent here is not to mimic a specific system but rather to demonstrate methods that can be applied to any system to obtain a simplified description of contaminant transport that can be defensibly used in long-term risk assessments.

Two of the most likely scenarios for radionuclide transport in crystalline rock (after being release from an engineered isolation system) are: (1) rapid advective transport through fractures in the host rock formation and/or (2) sorption of radionuclides to mobile native colloids or to colloids produced from engineered barrier materials (Dai et al, 2012; Huber et al., 2011; Liu et al., 2009; Liu et al., 2008). In order to assess and manage the risk of transport in rock systems that will be unique to each repository's geographic location, a general methodology would be helpful. Some of the important steps would be to (1) characterize potential flowpath surfaces, (2) interrogate radionuclide/geologic material interactions and kinetic rates of those interactions, and (3) model scenarios ranging from the most conservative (worst case) through more realistic cases with qualified uncertainties. This approach would provide a tool for decision makers to incorporate risk, sound science, and the need to eventually make a decision as the risk of doing nothing (surface storage) begins to exceed the risk of subsurface repository disposal strategies. This paper will focus on interpretation of batch and column experiments with uranium and $\mathrm{pH}$ changes to help develop methodologies to evaluate the dominant parameters for a more general assessment tool. 


\section{Materials and Methods}

\subsection{Porous media}

Granodiorite rock cores were collected from borehole CFM 11.002 at the Grimsel Test Site (GTS) in Switzerland and shipped to Los Alamos National Laboratory for processing. Cores were crushed using a percussion mortar, sieved into 75-150, 150-355, and 355-500 $\mu \mathrm{m}$ size fractions, thoroughly rinsed in high-purity water (Millipore, Milli-Q ${ }^{\circledR},>18 \mathrm{M} \Omega \mathrm{cm}$ resistivity), oven dried for 12 hours at $60{ }^{\circ} \mathrm{C}$, and stored in centrifuge tubes until use. Optical microscope (Wild Heerbrugg, M420) microphotographs show that, although the three size fractions of crushed granodiorite used in the following experiments vary in size by a factor of 7 , the relative abundance of light and dark grains appears to remain fairly consistent (Fig. 1). 


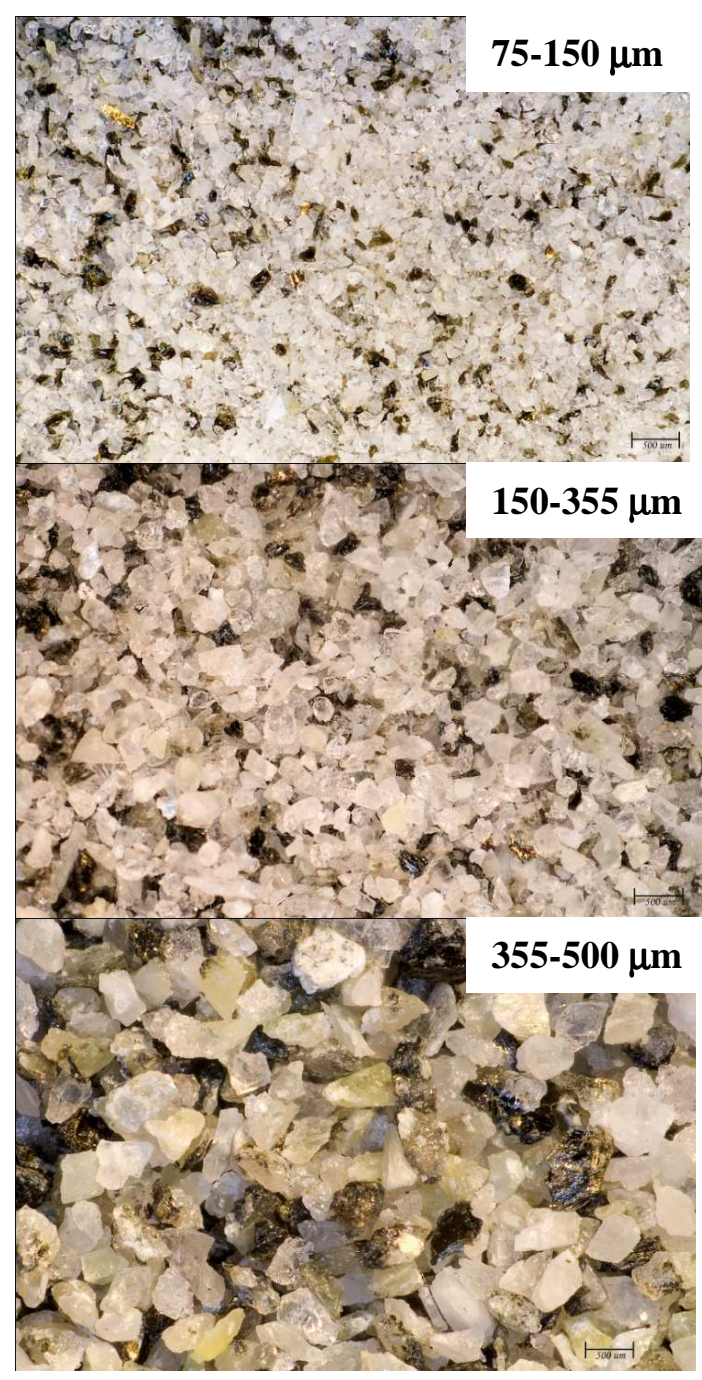

Figure 1. Microphotographs of the three different grain sizes of crushed and sieved Grimsel granodiorite. $500 \mu \mathrm{m}$ scale bars are shown in the lower right corner of each image.

Rock samples were characterized by quantitative $\mathrm{x}$-ray diffraction (QXRD) analysis and used in batch sorption and column breakthrough experiments (Table 1). The bulk chemical analysis of the unaltered granodiorite and the weathered granodiorite (fracture fill material, or FFM) adjacent to and occupying the fractures was measured by $\mathrm{x}$-ray florescence (Table 2). 
Table 1. Quantitative X-ray diffraction interpretation (wt\%) of Grimsel granodiorite materials.

\begin{tabular}{|c|c|c|c|c|c|c|c|c|}
\hline Sample & 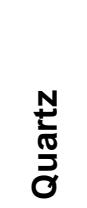 & $\begin{array}{l}\frac{\Phi}{\mathscr{D}} \\
\frac{\pi}{0} \\
\frac{0}{0} \\
\frac{\pi}{\alpha}\end{array}$ & 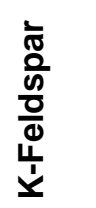 & $\stackrel{\mathscr{0}}{\Sigma}$ & 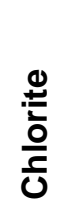 & 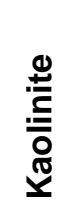 & $\begin{array}{l}\text { ॠथ } \\
\frac{0}{0} \\
\frac{0}{2}\end{array}$ & Total \\
\hline $75-150 \mu \mathrm{m}$ & 42.9 & 27.5 & 4.2 & 24.9 & 0.2 & 0.4 & --- & 101.1 \\
\hline $150-355 \mu \mathrm{m}$ & 24.3 & 43.8 & 7.8 & 23.6 & 0.2 & 0.2 & --- & 99.9 \\
\hline $355-500 \mu \mathrm{m}$ & 15.3 & 46.4 & 6.7 & 30.9 & 0.2 & 0.5 & --- & 100.0 \\
\hline
\end{tabular}

Table 2. X-ray fluorescence analysis (wt $\%$ ) of Grimsel materials.

\begin{tabular}{|c|c|c|c|}
\hline $\begin{array}{l}\text { Constituent } \\
\text { fuse ratio } \\
\end{array}$ & $\begin{array}{c}\text { Granodiorite } \\
\text { bulk } \\
7: 1 \\
\end{array}$ & $\begin{array}{c}\text { FFM } \\
\text { bulk } \\
7: 1 \\
\end{array}$ & $\begin{array}{c}\text { Detection } \\
\text { Limits } \\
7: 1 \\
\end{array}$ \\
\hline $\mathrm{Na}_{2} \mathrm{O}$ & 4.01 & 3.15 & 0.0451 \\
\hline $\mathrm{MgO}$ & 0.725 & 4.28 & 0.0300 \\
\hline $\mathrm{Al}_{2} \mathrm{O}_{3}$ & 14.0 & 14.3 & 0.0313 \\
\hline $\mathrm{SiO}_{2}$ & 70.9 & 63.4 & 0.1507 \\
\hline $\mathrm{P}_{2} \mathrm{O}_{5}$ & 0.115 & 0.124 & 0.0049 \\
\hline $\mathrm{K}_{2} \mathrm{O}$ & 4.22 & 4.90 & 0.0112 \\
\hline $\mathrm{CaO}$ & 1.90 & 1.03 & 0.0084 \\
\hline $\mathrm{TiO}_{2}$ & 0.436 & 0.491 & 0.0092 \\
\hline $\mathrm{MnO}$ & 0.081 & 0.086 & 0.0252 \\
\hline $\mathrm{Fe} 2 \mathrm{O}_{3}$ & 3.10 & 3.83 & 0.0041 \\
\hline $\mathrm{V}$ & 29 & 41 & 13 \\
\hline $\mathrm{Cr}$ & bdl & bdl & 10 \\
\hline Co & bdl & bdl & 15 \\
\hline $\mathrm{Ni}$ & bdl & bdl & 5 \\
\hline $\mathrm{Cu}$ & bdl & bdl & 5 \\
\hline $\mathrm{Zn}$ & 31 & 53 & 5 \\
\hline $\mathrm{Ge}$ & bdl & bdl & 24 \\
\hline As & bdl & bdl & 15 \\
\hline $\mathrm{Rb}$ & 110 & 192 & 4 \\
\hline $\mathrm{Sr}$ & 135 & 71 & 5 \\
\hline $\mathrm{Zr}$ & 217 & 236 & 6 \\
\hline $\mathrm{Ba}$ & 403 & 372 & 19 \\
\hline $\mathrm{W}$ & bdl & bdl & 43 \\
\hline $\mathrm{U}$ & bdl & bdl & 4 \\
\hline LOI & 0.35 & 4.28 & \\
\hline $\begin{array}{l}\text { total } \\
\text { bdl = below } \\
\text { LOI = loss } \mathrm{o}\end{array}$ & $\begin{array}{l}\qquad 99.931 \\
\text { detection limit } \\
\text { n ignition }\end{array}$ & 99.970 & \\
\hline
\end{tabular}


Although the FFM was not used in the experiments presented here, future work will focus on FFM because the vast majority of flow is expected to occur in fractures. The granodiorite data is intended to represent the worst-case scenario for transport, as the FFM is expected to have more attenuation potential due to its significant weathering and enrichment in clay minerals. The bulk chemical differences between the FFM and unaltered granodiorite are minor, with significant enrichment of $\mathrm{Mg}$, minor enrichments of $\mathrm{K}$ and $\mathrm{Fe}$, and minor depletions of $\mathrm{Si}, \mathrm{Na}$ and $\mathrm{Ca}$ in the FFM compared to the granodiorite.

One sample of crushed granodiorite in the $75-150 \mu \mathrm{m}$ size range was analyzed for surface area using the BET gas adsorption method with $\mathrm{Kr}$ as a sorbent. The specific surface area of this sample was determined to be $0.142 \mathrm{~m}^{2} / \mathrm{g}$. The specific surface areas of the $150-355 \mu \mathrm{m}$ and 355 $500 \mu \mathrm{m}$ granodiorite size fractions were not measured, but FFM samples in these size ranges were found to be 0.71 and 0.53 times the specific surface area of a 75-150 $\mu \mathrm{m}$ FFM sample. Assuming these ratios apply to the granodiorite, the specific surface areas of the $150-355 \mu \mathrm{m}$ and 355-500 $\mu \mathrm{m}$ granodiorite samples would be 0.10 and $0.075 \mathrm{~m}^{2} / \mathrm{g}$, respectively.

\subsection{Synthetic groundwater}

The groundwater used in all experiments was a synthetic Grimsel groundwater (SGGW) adjusted for additional constituents from the FEBEX bentonite packing material planned to be used as an engineered barrier to isolate waste packages within a repository. The recipe is given in Table 3. All solutions were made with high-purity water and analytical-grade reagents. SGGW in equilibrium with the atmosphere has a $\mathrm{pH}$ of 8.8-9.1. 
Table 3. Synthetic Grimsel

groundwater recipe.

\begin{tabular}{cc}
\hline Compound & $\mathrm{g} \mathrm{L}^{-1}$ \\
\hline $\mathrm{Na}_{2} \mathrm{SO}_{4}$ & 0.1440 \\
$\mathrm{KCl}$ & 0.0048 \\
$\mathrm{MgCO}_{3}$ & 0.0427 \\
$\mathrm{NaHCO}_{3}$ & 0.2733 \\
$\mathrm{CaCl}_{2}$ & 0.0130 \\
$\mathrm{H}_{4} \mathrm{SiO}_{4}$ & 0.0341 \\
\hline $\mathrm{pH}$ & $8.8-9.1$ \\
\hline
\end{tabular}

2-(N-morpholino)ethanesulfonic acid (MES) was used to buffer the $\mathrm{pH}$ for all experimental solutions below $\mathrm{pH} 8.9$ (6.9 and 7.9 solutions), and a 0.01 M MES solution was found to buffer the SGGW near $\mathrm{pH}$ 6.9. MES was selected as a buffer due to effective buffering in the pH 6-8 range while having a low tendency to complex with metal ions (Good et al., 1966), including uranyl ion $\left(\mathrm{U}(\mathrm{VI})^{2+}\right)$. Buffering with inorganic acid/base pairs such as carbonate or phosphate could affect the aqueous speciation and transport behavior of uranium by forming uranyl complexes (carbonate) and possibly uranyl precipitates (phosphate). The use of MES as a buffer for uranium and actinide studies also follows examples set by others (Giammar and Hering, 2001).

\subsection{Uranium and tritiated water}

The uranium used in all experiments was a combination of ${ }^{233} \mathrm{U}$ (Eckert and Ziegler) and natural uranium from a $1 \mathrm{~g} \mathrm{~L}^{-1} \mathrm{ICP}-\mathrm{MS}$ standard (SpexCertiPrep). For all uranium solutions, approximately $98 \%$ of the uranium (mostly ${ }^{238} \mathrm{U}$ ) was from the ICP-MS standard, and about $2 \%$ was ${ }^{233} \mathrm{U}$ added to ensure rapid, accurate, and inexpensive quantification by liquid scintillation counting. It was assumed that the ${ }^{233} \mathrm{U}$ and ${ }^{238} \mathrm{U}$ would behave identically with respect to adsorption and speciation in all experiments, as isotopic fractionation is expected to be minimal for sorption reactions without redox and/or precipitation (Ilton et al., 2012; Crançon al., 2010) . 
A groundwater concentration of $6.5 \mu \mathrm{M}$ uranium was used, and this concentration was experimentally verified to be under the solubility limit for the $\mathrm{pH}$ range of 6.9 to 9.1 . Equilibrium speciation calculations using PHREEQC (Parkhurst and Appelo, 2013) also predicted uranium to be below the solubility limit for all solutions (with the exception of a slight supersaturation with respect to soddyite, $\left(\mathrm{UO}_{2}\right)_{2} \mathrm{SiO}_{4} \cdot 2 \mathrm{H}_{2} \mathrm{O}$, at $\mathrm{pH}$ 6.9). Tritium in the form of tritiated water was used as an ideal tracer and co-injected with uranium to provide mean groundwater residence times and to allow for the calculation of dispersivity coefficients in the columns.

The target pHs of the MES-buffered SGGW were 6.9 and 7.9. Table 4 shows relative abundances of uranium-bearing species in SGGW as predicted by PHREEQC (Parkhurst and Appelo, 2013) using the llnl.dat database (Johnson, 2010) with the addition of uranyl-calciumcarbonate and uranyl-magnesium-carbonate complexation constants from Dong and Brooks (2006).

Table 4. Fractional abundance of uranium-bearing species in SGGW as a function of $\mathrm{pH}$ (from PHREEQC).

\begin{tabular}{cccc}
\hline Constituent & $\mathbf{p H ~ 6 . 9}$ & $\mathbf{p H ~ 7 . 9}$ & $\mathbf{p H ~ 8 . 8}$ \\
\hline $\mathrm{UO}_{2} \mathrm{Ca}\left(\mathrm{CO}_{3}\right)_{3}{ }^{2-}$ & 0.478 & 0.562 & 0.563 \\
$\mathrm{UO}_{2} \mathrm{Mg}\left(\mathrm{CO}_{3}\right)_{3}{ }^{2-}$ & 0.181 & 0.217 & 0.230 \\
$\mathrm{UO}_{2}\left(\mathrm{CO}_{3}\right)_{2}{ }^{2-}$ & 0.141 & 0.0171 & 0.00261 \\
$\mathrm{UO}_{2} \mathrm{Ca}_{2}\left(\mathrm{CO}_{3}\right)^{3}$ & 0.0868 & 0.0998 & 0.0900 \\
$\mathrm{UO}_{2}\left(\mathrm{CO}_{3}\right)_{3}{ }^{4-}$ & 0.0785 & 0.0943 & 0.105 \\
$\mathrm{UO}_{2}\left(\mathrm{CO}_{3}\right)^{0}$ & 0.0180 & 0.00022 & --- \\
$\mathrm{UO}_{2} \mathrm{Mg}_{2}\left(\mathrm{CO}_{3}\right)_{3}{ }^{0}$ & 0.00790 & 0.00935 & 0.00943 \\
$\mathrm{UO}_{2}(\mathrm{OH})^{+}$ & $8.5 \mathrm{e}-5$ & $1.1 \mathrm{e}-6$ & $2.4 \mathrm{e}-8$ \\
$\mathrm{UO}_{2}{ }^{2+}$ & $2.5 \mathrm{e}-6$ & $1.9 \mathrm{e}-9$ & $8.8 \mathrm{e}-12$ \\
\hline $\mathrm{SUM}$ & $\mathbf{0 . 9 9 1 0}$ & $\mathbf{0 . 9 9 9 3}$ & $\mathbf{0 . 9 9 9 9}$ \\
\hline
\end{tabular}

Uranium adsorption partition coefficients ( $K_{d}$ values) for many different minerals have been reported to vary over several orders of magnitude between pH 7 and 9 (Joseph et al., 2013; 
Kaplan and Serkiz, 2004; Missana et al., 2004; M $\square$ ri, 2004; Davis and Curtis, 2003; Echevarria et al, 2001; Waite et al., 1994), with $K_{d}$ values of essentially zero at pH greater than 9. For a given $p \mathrm{CO}_{2}$, uranium exhibits much stronger adsorption at $\mathrm{pH}$ near 7 because of the greater abundance of positively-charged uranyl species $\left(\mathrm{UO}_{2}{ }^{2+}\right.$ and $\left.\mathrm{UO}_{2}(\mathrm{OH})^{+}\right)$and less abundance of nonsorbing neutral and negatively-charged uranyl carbonate or uranyl-Ca/Mg-carbonate complexes.

\subsection{Analytical measurements}

Tritium and uranium concentrations were measured by liquid scintillation counting, or LSC (Perkin-Elmer Tri-Carb 2550 or Perkin-Elmer Quantulus), with energy ranges of 0-18.6 $\mathrm{keV}$ for tritium and $100-260 \mathrm{keV}$ for uranium. An aliquot of a groundwater sample was weighed, diluted to $6 \mathrm{~mL}$ with high-purity water, and poured into a $20 \mathrm{~mL}$ polypropylene scintillation vial with $14 \mathrm{~mL}$ of liquid scintillation cocktail (PerkinElmer, Ultima Gold ${ }^{\mathrm{TM}} \mathrm{AB}$ ). Samples were counted for two 15 minute increments and the average was used to yield counts per minute per $\mathrm{mL}$ or $\mathrm{CPM} \mathrm{mL} \mathrm{m}^{-1}$. The transformed index of an external standard (tSIE) was used to adjust for variable quenching of the samples. $\mathrm{pH}$ measurements were made using a pH meter (Orion, Model 290) and a glass $\mathrm{pH}$ electrode (Fisher, AccupHast) calibrated with pH 4.01, 7.00 and 9.01 buffers.

\subsection{Batch adsorption experiments}

Batch adsorption experiments were conducted with the 150-355 $\mu \mathrm{m}$ fraction of crushed granodiorite material at $\mathrm{pH} 6.9$ and 8.8. $12 \mathrm{~mL}$ of uranium-spiked SGGW $(6.5 \mu \mathrm{M} \mathrm{U})$ and 0.2 , 0.5 , or $1.0 \mathrm{~g}$ of granodiorite were added to $50-\mathrm{mL}$ polypropylene centrifuge tubes. Control experiments without the geologic materials present were conducted at each $\mathrm{pH}$ to evaluate 
adsorption to container walls. The experimental matrix is summarized in Table 5 and all experiments were conducted in duplicate. The relatively short-duration experiments were conducted mainly to place constraints on adsorption rate constants in the uranium-SGGWgranodiorite system.

Table 5. Batch adsorption experimental matrix.

\begin{tabular}{ccc}
\hline Material & SGGW pH $=6.9$ & SGGW pH = 8.8 \\
\hline 0.2 g Granodiorite & $1,10,100,1000 \mathrm{~min}$ & $1,10,100,1000 \mathrm{~min}$ \\
0.5 g Granodiorite & $1,10,100,1000 \mathrm{~min}$ & $1,10,100,1000 \mathrm{~min}$ \\
1.0 g Granodiorite & $1,10,100,1000 \mathrm{~min}$ & $1,10,100,1000 \mathrm{~min}$ \\
Control (no rock) & $1,10,100,1000 \mathrm{~min}$ & $1,10,100,1000 \mathrm{~min}$ \\
\hline
\end{tabular}

The centrifuge tubes were vertically positioned on an orbital shaker (VWR Scientific, DS-500) and horizontally oscillated at 180 RPM (Fig. 2).

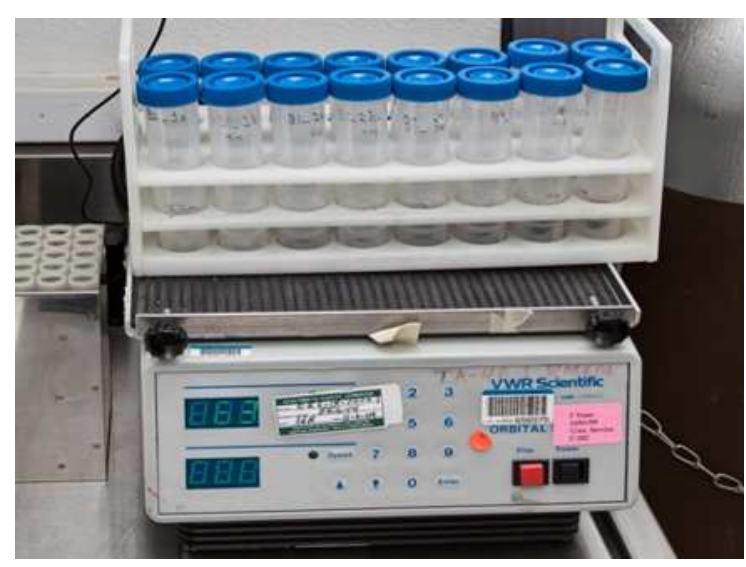

Figure 2. Image of granodiorite batch adsorption-desorption experimental setup.

The tubes were also manually inverted several times at least once a day to ensure adequate mixing of the media and solution.

$1 \mathrm{~mL}$ samples were collected after 1,10,100, and 1000 minutes and were measured for total uranium concentration. The solution removed for analysis was not replaced. At the end of 
the experiments, the $\mathrm{pH}$ of the remaining solution in the centrifuge tubes was measured to determine if it had drifted during the experiments. Additional batch experiments were conducted with various column experiment components to evaluate adsorption and to aid in material selection. These components included Tygon ${ }^{\circledR}$ tubing (R-3603), polyethylene tubing used for columns, and glass wool used as a fill material at the ends of some columns.

\subsection{Column transport experiments}

Small columns were constructed from $6.5 \mathrm{~cm}$ lengths of $1 \mathrm{~cm}$ diameter polyethylene tubing. These small columns were devised to allow rapid and economical evaluation of sorption/desorption behavior under flowing conditions (and in duplicate or triplicate). The inside of the ends of the polyethylene columns were tapped to accept threaded polyethylene fittings with hose barbs on one end. Tygon ${ }^{\circledR}$ tubing (R-3606) and 3-way polycarbonate stopcocks were used to connect the columns to $60 \mathrm{~mL}$ polypropylene syringes (BD Falcon) at the bottom (influent side) of the column. Columns were wet-packed with $5.0 \mathrm{~g}$ of material by incrementally adding $\sim 0.25 \mathrm{~g}$ of material to a column with solution ponded in the bottom. The columns were tapped to settle grains after sedimentation and to ensure uniform porosity between columns. A small amount of glass wool ( $\sim 0.04 \mathrm{~g})$ was used at the top and bottom to prevent grains from entering the tubing. Polypropylene syringes containing either uranium-bearing or uranium-free solution were loaded into syringe pumps (KD Scientific, Model 100) that were set to a flow rate of $0.3 \mathrm{~mL} \mathrm{~h}^{-1}$. Flow was directed upward to help maintain saturation and to minimize the potential for air bubbles collecting in the column. An additional length of Tygon ${ }^{\circledR}$ tubing was connected to the barb on the top of the column and directed column effluent to a fraction collector (Gilson, FC-220) filled with $13 \times 100 \mathrm{~mm}$ polyethylene test tubes. The fraction 
collectors were enclosed in an acrylic plastic chamber with an evaporation pan to limit evaporation of samples before analysis (Fig. 3).

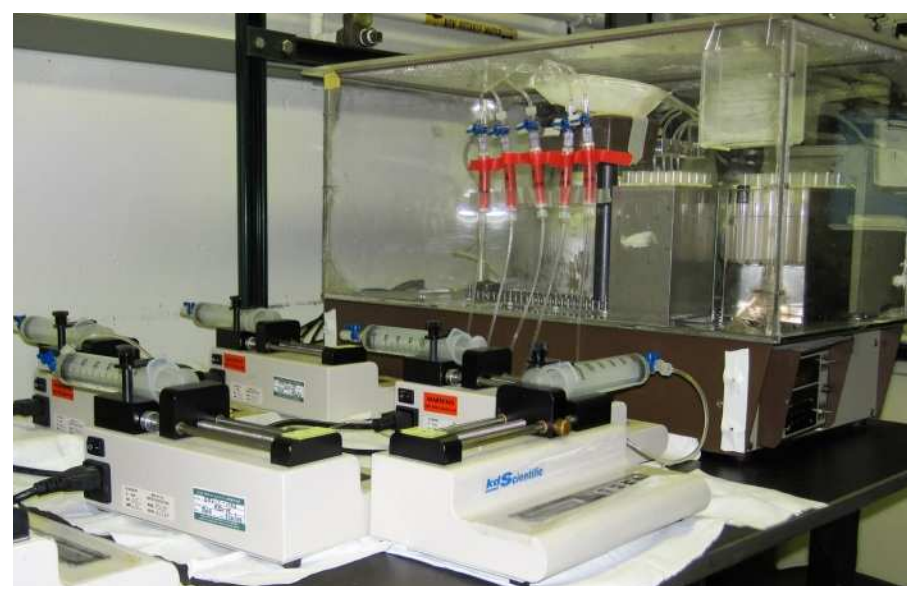

Figure 3. Image of column setup with 5 columns running in parallel.

The columns were initially flushed with uranium-free SGGW until the effluent $\mathrm{pH}$ stabilized to within $0.1 \mathrm{pH}$ units of the influent solution. The influent solution was then switched to solution containing uranium and tritium. Syringes were refilled several times during the course of the experiments and were eventually changed to uranium- and tritium-free solution to observe desorption behavior in the column. Samples were collected at increments ranging from 90 minutes for early samples to 900 minutes for later samples and sample mass was weighed with a digital balance (Mettler, PL1200) to determine actual flow rates. pH measurements were recorded for all samples from one of the duplicate columns.

The column experimental summary is provided in Table 6. Flow interruptions, flow rate changes, and influent $\mathrm{pH}$ changes were introduced to help elucidate uranium adsorption and desorption mechanisms. Three size fractions were used (75-150 $\mu \mathrm{m}, 150-355 \mu \mathrm{m}$, and 355-500 $\mu \mathrm{m})$ and were run in triplicate. Actual flow rates in all columns were calculated to be approximately $0.27 \mathrm{~mL} \mathrm{~h}^{-1}$. 
Table 6. Summary of solution chemistry and flow rates changes for column experiments.

\begin{tabular}{ccc}
\hline Conditions & $\begin{array}{c}\text { Approximate Start } \\
\text { Time, } \mathbf{~ h r}\end{array}$ & $\begin{array}{c}\text { Approximate Start } \\
\text { Volume, } \mathbf{~ L L}\end{array}$ \\
\hline Inject 6.5 mM U at pH 7.2 & 0 & 0 \\
Inject U-free SGGW, pH 6.7 & 340 & 90 \\
30-day Flow Interruption & $575(1290 \mathrm{end})$ & 160 \\
7-hr Flow Interruption & 1380 & 185 \\
4-day Flow Interruption & $1425(1520 \mathrm{end})$ & 200 \\
Double Flow Rate (approx.) & 1650 & 240 \\
Halve Flow Rate and pH to 7.2 & 1770 & 295 \\
pH to 8.8 & 1900 & 330 \\
\hline
\end{tabular}

\subsection{Interpretive modeling}

The batch and column experiments were interpreted using a multi-site/multi-rate reaction modeling approach where each different type of site could be assigned different adsorption and desorption rate constants and different surface site densities. Separate Fortran programs were used for modeling the two different types of experiments, although the equations used to model the adsorption and desorption reactions in each program were identical. The governing equations in the batch experiment model were:

$\frac{\partial s_{i}}{\partial t}=k_{f i} c\left(1-\frac{s_{i}}{s_{m i}}\right)-k_{r i} s_{i}$

$\frac{\partial c}{\partial t}=\frac{M}{V}\left[-\sum_{i} k_{f i} c\left(1-\frac{s_{i}}{s_{m i}}\right)+\sum_{i} k_{r i} s_{i}\right]$

where, $c=$ concentration in aqueous phase, $\mathrm{mol} \mathrm{mL}^{-1}$

$s_{i}=$ concentration on surface sorption site $\mathrm{i}, \mathrm{mol} \mathrm{g}^{-1}$

$t=$ time, $\mathrm{h}$ 
$k_{f i}=$ adsorption rate constant for sorption site $\mathrm{i}, \mathrm{mL} \mathrm{g}^{-1} \mathrm{~h}^{-1}$

$k_{r i}=$ desorption rate constant for site $\mathrm{i}, \mathrm{h}^{-1}$

$s_{m i}=$ surface site density (maximum adsorption capacity) for sorption site $\mathrm{i}, \mathrm{mol} \mathrm{g}^{-1}$

$M=$ mass of solids, $\mathrm{g}$

$V=$ volume of solution, $\mathrm{mL}$

The governing equations for the column transport model were Eq. 1 plus the following equation for the mobile aqueous phase:

$\frac{\partial c}{\partial t}-v \frac{\partial c}{\partial x}+D \frac{\partial^{2} c}{\partial x^{2}}+\frac{\rho_{B}}{\emptyset}\left[-\sum_{i} k_{f i} c\left(1-\frac{s_{i}}{s_{m i}}\right)+\sum_{i} k_{r i} s\right]$

where, $v=$ flow velocity, $\mathrm{cm} \mathrm{h}^{-1}$

$D=$ dispersion coefficient, $\mathrm{cm}^{2} \mathrm{~h}^{-1}$

$\rho_{B}=$ bulk density of solids, $\mathrm{g} \mathrm{cm}^{-3}$

$\varphi=$ porosity

In addition to solving equations (1) and (2), the batch model allowed the volume of solution in the reactor to be changed at specified times to account for sampling losses. Equations (1) and (2) were solved using a $4^{\text {th }}$-order Runge-Kutta algorithm.

The column model solved equations (1) and (3) simultaneously using an implicit finite difference algorithm. The model allowed for varying injection functions to be specified at the column entrance $(x=0)$. It also allowed for flow rate changes and changes to the reaction parameters $k_{f i}, k_{r i}$, and $s_{m i}$ at multiple times during a simulation. Changes to the reaction parameters could be specified when the $\mathrm{pH}$ of the injection solution was changed or when a transition was made from injecting uranium-spiked water to uranium-free water (to simulate adsorption-desorption hysteresis). The changes to reaction parameters were propagated through the columns in the same manner as a conservative tracer.

Our modeling approach was to try to simultaneously match the combined data from both the batch and column experiments using a single set of reaction parameters and a minimal 
number of sorption site types. By matching both the batch and column data, the reaction parameters were more highly constrained than if the data from only one type of experiment were matched. The goal was to use only as many site types as necessary to achieve a reasonable qualitative match to the data. An automated parameter estimation algorithm, such as PEST (Doherty, 2010, 2009), was not employed to obtain the matches to the data. It was considered more important to match subtle data features containing only a few observations even if it meant a poorer match to features containing many data points that would have dominated a leastsquares or other minimization exercise.

\section{Results}

\subsection{Batch sorption experiments}

The $\mathrm{pH} 8.8$ batch adsorption experiments indicated no measurable adsorption of uranium to the granodiorite. Figure 4 shows the data from the $\mathrm{pH} 6.9$ batch adsorption experiments along with model curves that represent simultaneous matches to both the batch and column breakthrough data. The solid model curves of Figure 4 were generated using the rate constants and site densities that provided good matches to the initial $\mathrm{pH} 7.2$ portion of the breakthrough curves in the column experiments using the $150-355 \mu \mathrm{m}$ granodiorite sizefraction (the same size fraction as in the batch experiments). The $\mathrm{pH} 7.2$ parameters from the column experiments (first set of parameters in Table 7 of Section 3.3) were used instead of the $\mathrm{pH} 6.7$ parameters because the $\mathrm{pH}$ in the batch experiments drifted upward from a starting $\mathrm{pH}$ of 6.9 to final $\mathrm{pHs}$ of 7.25 , 7.49, and 7.83 in the experiments with $0.2 \mathrm{~g}, 0.5 \mathrm{~g}$, and $1.0 \mathrm{~g}$ of granodiorite, respectively (the batch control experiments drifted up to $\mathrm{pH}$ 7.06). 


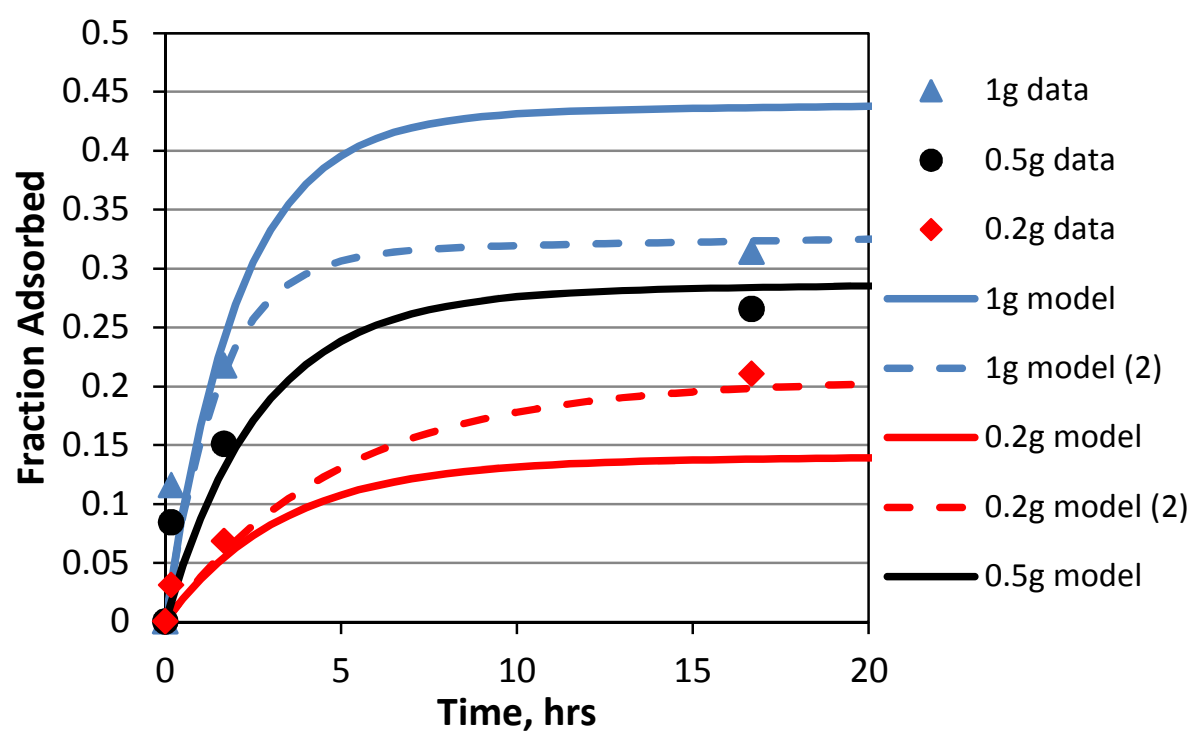

Figure 4. Granodiorite batch sorption data and model results for experiments with a starting $\mathrm{pH}$ of 6.9. Data points are averages of two observations and are corrected for interactions observed in control experiments. The solid curves were obtained using adsorption and desorption rate constants of $2.5 \mathrm{ml} / \mathrm{g}-\mathrm{hr}$ and $0.25 \mathrm{hr}^{-1}$, respectively, for the first adsorption site (approximately the same as for the first site at a $\mathrm{pH}$ of 7.2 in the column experiments). The dashed curves (labeled "model (2)") were obtained using the same adsorption rate constant but with desorption rate constants of $0.15 \mathrm{hr}^{-1}$ for the $0.2 \mathrm{-g}$ experiments and $0.43 \mathrm{hr}^{-1}$ for the 1.0 -g experiments.

The dashed curves of Figure 4 correspond to improved fits to the 0.2 and $1.0 \mathrm{~g}$ data sets after adjusting the desorption rate constant of the first sorption site. The desorption rate constant for the $0.2 \mathrm{~g}$ experiments was decreased from 0.25 to $0.15 \mathrm{hr}^{-1}$ and the desorption rate constant for the $1.0 \mathrm{~g}$ experiments was increased from 0.25 to $0.43 \mathrm{hr}^{-1}$. These adjustments were considered justified because uranium is known to adsorb more strongly at lower $\mathrm{pHs}$ in the $\mathrm{pH}$ range from 6 to 8 (Vandenhove et al., 2009). Given that the final $\mathrm{pH}$ was lowest in the $0.2 \mathrm{~g}$ experiments, it is reasonable that the desorption rate constant would be smallest in the $0.2 \mathrm{~g}$ experiments. We note that the trend of less uranium adsorption per unit mass of solids as the solids mass increased in the batch experiments is the opposite of what is expected for a nonlinear adsorption isotherm, which has frequently been observed for uranium on various mineral 
surfaces (Arnold et al., 2011; Dean, 2010; Davis, 2001; Kohler and Davis, 2001; Kohler et al., 1996; Waite et al., 1994). We attribute this trend to the tendency for uranium to adsorb more strongly at the lower $\mathrm{pHs}$ of the experiments with lower solid-to-solution ratios. We likely would have seen the expected trend if the $\mathrm{pH}$ had been constant in all the experiments.

The adsorption rate constants were kept the same for all experiments ( $2.5 \mathrm{ml} / \mathrm{g}$-hr), so a smaller desorption rate constant translates to a greater effective partition coefficient $\left(K_{d}=k_{f} k_{r}\right)$, and a larger desorption rate constant translates to a smaller effective partition coefficient. The model curves were not sensitive to the rate constants and surface densities of the second and third sites because the batch experiments were too short to observe the contribution of these slower sites. In effect, the batch experiments were useful for helping constrain the adsorption and desorption rate constants of only the first site in the column experiments. The surface coverage of uranium at the end of the 0.2 -g batch experiments was calculated to be 0.78 $\mu$ moles $/ \mathrm{m}^{2}$, which is about $40 \%$ of the total uranium sorption site density of $1.92 \mu$ moles $/ \mathrm{m}^{2}$ for silicate surfaces used by Davis and Curtis (2003), whereas the surface coverages in the 0.5-g and 1.0-g batch experiments were calculated to be 0.39 and $0.23 \mu$ moles $/ \mathrm{m}^{2}$, respectively.

The solutions were predicted by PHREEQC calculations predicted the solutions to be slightly supersaturated with respect to amorphous $\mathrm{SiO}_{2}$ and soddyite $\left(\left(\mathrm{UO}_{2}\right)_{2} \mathrm{SiO}_{4} \cdot 2 \mathrm{H}_{2} \mathrm{O}\right)$ at $\mathrm{pH}$ 6.9, suggesting that there could have been some uranium sorption and/or precipitation during the batch experiments. However, the $6.5 \mu \mathrm{M}$ uranium stock solution stored in a Teflon ${ }^{\circledR}$ bottle and buffered to $\mathrm{pH} 6.9$ remained stable with respect to uranium concentrations for periods much longer than the batch experiments. 


\subsection{Material interactions experiments}

The $\mathrm{pH} 7.2$ granodiorite column experiments were a challenge to interpret because of significant interactions between uranium and some of the column materials. Some simple batch experiments were conducted to screen for the uranium interactions with system components and to allow for quantification and correction (Fig. 5).

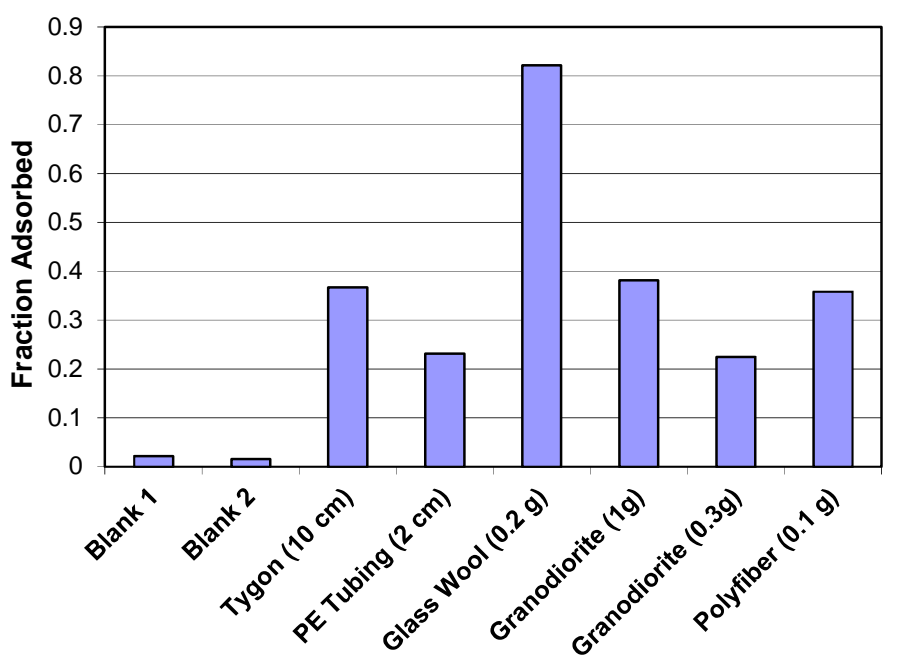

Figure 5. Uranium interactions with granodiorite column components in batch experiments (144 hrs, $10 \mathrm{ml}$ solution). Note: Polyfiber was not used in columns.

Column experiments conducted at $\mathrm{pH} 8.8$ and shown in Figure 6 indicate no measurable adsorption or retardation of uranium to either the granodiorite or to the materials used in these experiments (i.e., polyethylene columns and Tygon ${ }^{\circledR}$ tubing, R-3606). 


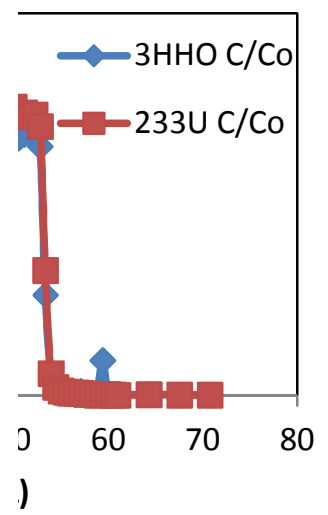

Figure 6. ${ }^{3} \mathrm{HHO}$ and uranium breakthrough curves from a granodiorite column experiment at $\mathrm{pH} 8.8$.

Results of the column system control experiments and model matches to the data are shown in Figure 7.

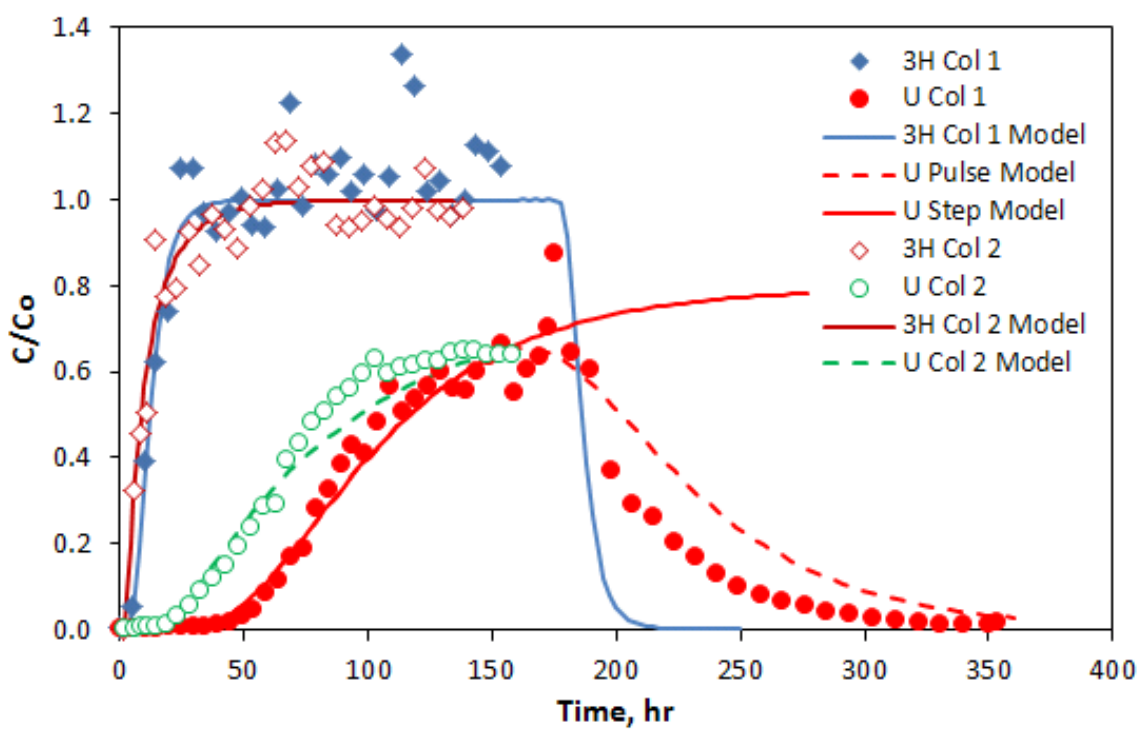

Figure 7. Tritium and uranium breakthrough curves in control columns at pH 7.2. Model parameters from red model curves were used to construct injection functions in granodiorite column experiments.

The model results of the control experiments with empty columns were used to simulate the injection pulse in the granodiorite experiments after accounting for the sorption effects of the other system components. To approximate the injection pulses in the granodiorite columns 
(which had longer injection pulses and less dispersion than the empty control columns), the attenuation parameters from the model fits in Figure 7 were used to predict the injection pulses.

Additional experiments (not shown here) were conducted to evaluate the influence of column components at $\mathrm{pH} 7.9$ and also to better quantify the effects of the glass wool on uranium transport at pH 7.2 (Dittrich et al., 2014; Dittrich and Reimus, 2013; Reimus and Dittrich, 2013). The pH 7.9 experiments included separate systems with either Tygon ${ }^{\circledR}$ or Teflon ${ }^{\circledR}$ tubing with polyethylene columns. It was apparent that there was less attenuation of uranium in the Tygon ${ }^{\circledR} / \mathrm{PE}$ control system at $\mathrm{pH} 7.2$, although attenuation was still significant enough to have to account for it. There was no attenuation of uranium relative to tritium in the Teflon ${ }^{\circledR} / \mathrm{PE}$ columns, suggesting that interactions with the PE columns at $\mathrm{pH} 7.9$ are minimal and the observed uranium attenuation in the Tygon ${ }^{\circledR} / \mathrm{PE}$ system is from interactions with the Tygon ${ }^{\circledR}$ tubing.

\subsection{Column experiments}

The data from the column experiments using the 75-150 $\mu \mathrm{m}, 150-355 \mu \mathrm{m}$, and $355-500$ $\mu \mathrm{m}$ size fraction of granodiorite are shown in Figure 8 overlaid with model simulations and simulated uranium injection functions that take into account uranium attenuation in the tubing and other column system components. Reaction parameters resulting in the model curves are listed in Table 7. 

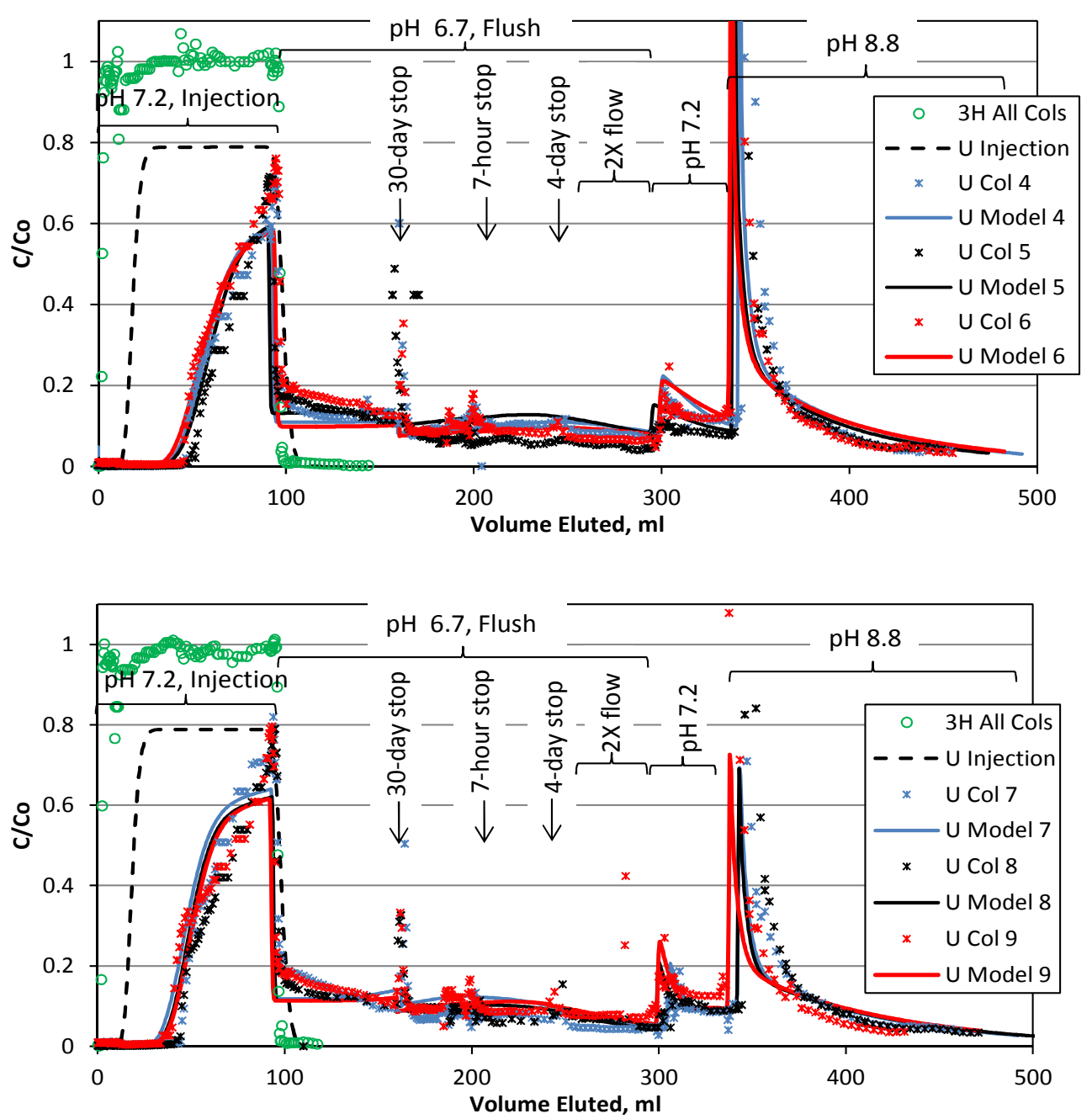

Figure 8. Tritium and uranium breakthrough curve data and model simulations for granodiorite size fractions of 75-150 $\mu \mathrm{m}$ (top), 150-355 $\mu \mathrm{m}$ (middle), and 355-500 $\mu \mathrm{m}$ (bottom). 
Table 7. Reaction model parameters yielding matches to granodiorite column transport data shown in Figure 8. In all cases, first number is for Site 1, second number is Site for 2, and the third number is for Site 3. Italic text indicates values that were varied for different size fractions.

\begin{tabular}{|c|c|c|c|}
\hline 75-150 $\mu \mathrm{m}$ material & $k_{f}, \mathrm{~mL} / \mathrm{g}-\mathrm{hr}$ & $k_{r}, \mathrm{hr}^{-1}$ & $S_{m}, \mu \mathrm{mol} / \mathrm{g}$ \\
\hline $\mathrm{pH} 7.2$ adsorption & $3.5,0.012,0.012$ & $(0.49 / 0.42)^{a}, 0.0025,0.001$ & $1.3,0.042,0.042$ \\
\hline pH 6.7 desorption & $3.5,0.012,0.012$ & $0.077,0.0001,0.0001$ & $1.3,0.042,0.042$ \\
\hline $\mathrm{pH} 7.2$ desorption & $3.5,0.012,0.012$ & $0.21,0.0025,0.001$ & $1.3,0.042,0.042$ \\
\hline pH 8.8 desorption & $1.0,0.5,0.2$ & $3.0,1.0,0.01$ & $1.3,0.042,0.042$ \\
\hline 150-355 $\mu \mathrm{m}$ material & $k_{f}, \mathrm{~mL} / \mathrm{g}-\mathrm{hr}$ & $k_{r}, \mathrm{hr}^{-1}$ & $S_{m}, \mu \mathrm{mol} / \mathrm{g}$ \\
\hline pH 7.2 adsorption & $2.5,0.0095,0.0095$ & $(0.46 / 0.42 / 0.35)^{a}, 0.0025,0.001$ & $1.3,0.042,0.042$ \\
\hline pH 6.7 desorption & $2.5,0.0095,0.0095$ & $0.077,0.0001,0.0001$ & $1.3,0.042,0.042$ \\
\hline pH 7.2 desorption & $2.5,0.0095,0.0095$ & $(0.21 / 0.14)^{a}, 0.0025,0.001$ & $1.3,0.042,0.042$ \\
\hline pH 8.8 desorption & $1.0,0.5,0.2$ & $3.0,1.0,0.01$ & $1.3,0.042,0.042$ \\
\hline $355-500 \mu \mathrm{m}$ material & $k_{f}, \mathrm{~mL} / \mathrm{g}-\mathrm{hr}$ & $k_{r}, \mathrm{hr}^{-1}$ & $S_{m}, \mu \mathrm{mol} / \mathrm{g}$ \\
\hline pH 7.2 adsorption & $1.3,0.0075,0.0075$ & $0.42,0.0025,0.001$ & $1.3,0.042,0.042$ \\
\hline pH 6.7 desorption & $1.3,0.0075,0.0075$ & $0.077,0.0001,0.0001$ & $1.3,0.042,0.042$ \\
\hline $\mathrm{pH} 7.2$ desorption & $1.3,0.0075,0.0075$ & $0.42,0.0025,0.001$ & $1.3,0.042,0.042$ \\
\hline $\mathrm{pH} 8.8$ desorption & $1.0,0.5,0.2$ & $3.0,1.0,0.01$ & $1.3,0.042,0.042$ \\
\hline
\end{tabular}

Figure 9 shows the $\mathrm{pH}$ and flow rate as a function of volume eluted in one of the $75-150 \mu \mathrm{m}$ size fraction granodiorite columns.

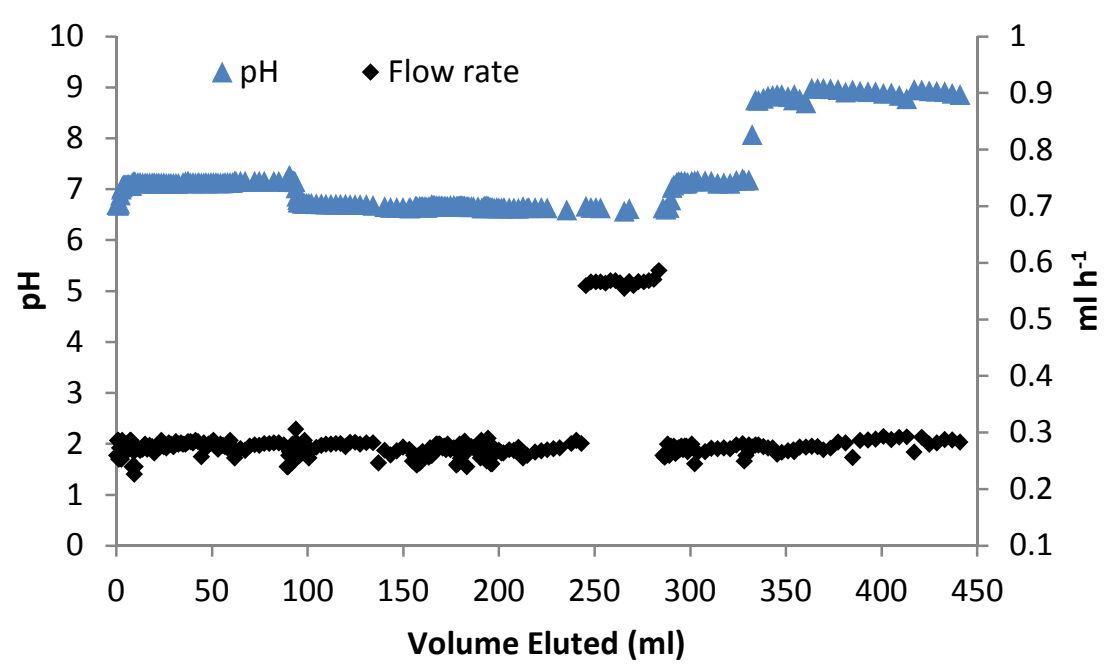

Figure 9. $\mathrm{pH}$ and flow rate history during column experiments (measured in a column containing 75-150 $\mu \mathrm{m}$ size fraction). 


\section{Discussion}

\subsection{Reaction parameters}

The reaction parameters of Table 7 are in excellent agreement for a given sieve size fraction, reflecting the high reproducibility of the experiments. Furthermore, the adsorption rate constants of the dominant sorption site (Site 1 in Table 7) scale almost exactly with the deduced specific surface areas of the granodiorite size fractions mentioned at the end of Section 2.1. The adsorption rate constants for Site 1 are 3.5, 2.5 and $1.8 \mathrm{~mL} / \mathrm{g}-\mathrm{hr}$ for the $75-150 \mu \mathrm{m}, 150-355 \mu \mathrm{m}$, and $355-500 \mu \mathrm{m}$ size fractions, respectively, and have the same ratio of values as the specific surface areas of $0.14,0.10$, and $0.075 \mathrm{~m}^{2} / \mathrm{g}$ for these size fractions. The adsorption rate constants for Sites 2 and 3 in Table 7 also have similar ratios, although they are not exactly the same as the ratios of the specific surface areas. Slight differences in reaction parameters for the replicate columns were allowed in recognition that there were potentially minor differences in the porosities and the material heterogeneity in the columns. Davis and Curtis (2003) used a maximum uranium sorption site density of $1.92 \mu$ moles $/ \mathrm{m}^{2}$ on silicate surfaces based on the recommendations of Davis and Kent (1990). In our modeling we assumed $\sim 1.3 \mu$ moles/g as a maximum surface site density, which implies a specific surface area of $\sim 0.68 \mathrm{~m}^{2} / \mathrm{g}$ (i.e., $1.3 / 1.92$ ) to be in agreement with the value used by Davis and Curtis (2003).

The adsorption and desorption rate constants of the first adsorption site (i.e., the site with the fastest rates and the largest site density) were not well constrained by the column experiments. The model fits were relatively insensitive to these rate constants provided that the ratio of the constants was fixed and that the rate constants exceeded some lower threshold value below which earlier-than-observed uranium breakthrough was predicted. The short-duration batch adsorption experiments (Fig. 4) helped constrain the adsorption rate constant to be 
approximately $2.5 \mathrm{~mL} / \mathrm{g}$-hr (much faster or slower rate constants would result in a poor match to the batch data). Several points are worth discussing with respect to the best-fitting reaction parameters of Table 7 and the uranium breakthrough curves of Figure 8. Although the parameters of Table 7 provide good matches to the column data sets, they should not necessarily be considered unique. There were some correlations noted between the parameters for a given site; for instance, similar results could be obtained by increasing the surface site density and decreasing the adsorption rate constant for a site (particularly for sites that have relatively small surface densities) while keeping the desorption rate constant approximately the same for that site. Davis and Curtis (2003) found a similar negative correlation between site densities and equilibrium constants for surface complexation reactions in their modeling efforts, which did not consider reaction kinetics. Also, the desorption rate constants of the second and third sites at $\mathrm{pH}$ 6.7 were not well constrained; these rate constants could be varied over a relatively large range from zero to $0.0003 \mathrm{hr}^{-1}$ without having much effect on the model curves. In effect, these rate constants could not be distinguished from zero. The range of reaction parameters resulting in reasonable fits to the $\mathrm{pH} 7.2$ column data was better constrained than for the $\mathrm{pH} 6.7$ data.

\subsection{Deductions about uranium adsorption and desorption processes from column experiments}

It is reasonable to question whether three different adsorption sites are really necessary to explain the column transport data, particularly since the last two sites have small surface densities and differ only in their desorption rate constants at $\mathrm{pHs}$ higher than 6.7. Figure 10 shows the results of sequentially fitting the data sets from one of the $75-150 \mu \mathrm{m}$ granodiorite column experiments (column 8) with one, two, and three adsorption sites. The results of this sequential fitting exercise for other column experiments were very similar and are not shown. The model parameters corresponding to the fits of Figure 10 are listed in Table 8. 
It is apparent that the ability of the model to fit the data is significantly improved by increasing the number of adsorption sites from one to two. A one-site model is not capable of 
matching the leveling-off of concentrations at $C / C_{0}$ values less than 1 during the uranium injection phase of the experiments or the slow desorption behavior observed later in the experiments. The incremental improvement of a three-site model over a two-site model is much more subtle, with an obvious improvement only during the late portion of the experiment where the $\mathrm{pH}$ was raised from 6.7 to 7.2. Here, the addition of a third site with a somewhat slower desorption rate constant than the second site provides a better fit to this small portion of the experiment.

Of particular interest for risk assessments over long time and distance scales is the sensitivity of the model fits to the slow desorption rate constants of the second and third sorption sites, as long-term model predictions are significantly affected by subtle differences in slow desorption rates. Figure 11 compares the three-site model curve of Figure 10 with a curve generated using the same parameters, except that the desorption rate constant of the third sorption site was set to zero. It is apparent that changing the desorption rate constant of the third site to zero had little overall effect on the model curve, which suggests that the column experiments were not conducted in a manner that would allow them to very accurately interrogate slow desorption rates at $\mathrm{pH}$ 7.2. The implications of this result are discussed in Section 4.3. 


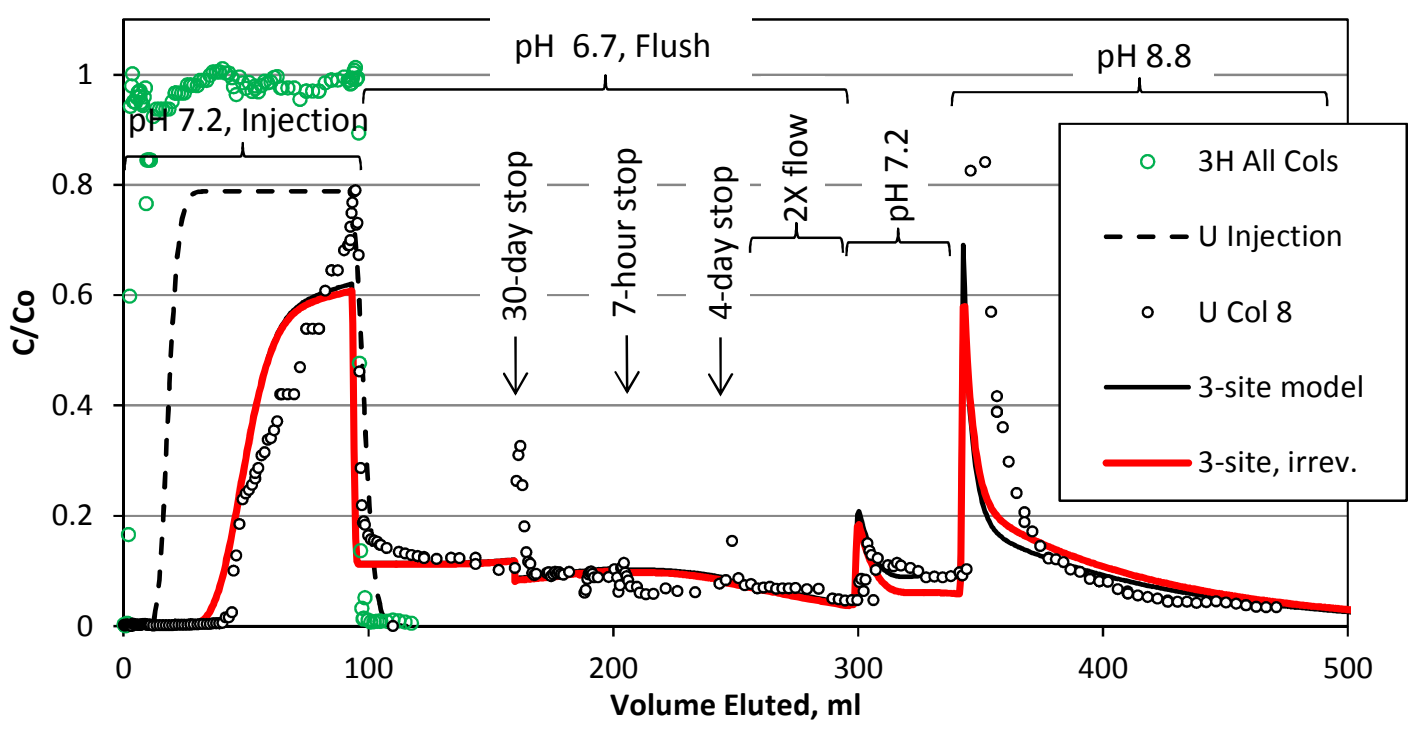

Figure 11. Uranium breakthrough column data (column 8) and model simulations comparing the three-site model with the desorption rate constants from Table 8 (black line) and the desorption rate constant of the third site set equal to zero (red line).

\subsection{Effect of geochemical and flow transients (e.g., pH, flow rate, flow interruptions)}

For the model to capture the abrupt drop in uranium concentrations immediately after the transition from injection of uranium-bearing water to uranium-free water, the desorption rate constant for all sorption sites had to be decreased significantly at the time of the transition. As Figure 9 shows, this abrupt decrease corresponded to a drop in $\mathrm{pH}$ from about 7.2 to 6.7, and given that uranium partitioning to solids is predicted to increase with such a $\mathrm{pH}$ change, the decrease in the desorption rate constants is reasonable. Increasing the adsorption rate constants would have a similar effect, but decreasing the desorption rate constants was more logical because the uranium was already adsorbed to the solids at the time of the $\mathrm{pH}$ change. The ability to capture the concentration drop with the model was most sensitive to the desorption rate constant of the first site, with the model being relatively insensitive to the second and third desorption rate constants. The effective partition coefficient for any given site is equal to the ratio of the adsorption to desorption rate constants (i.e., $K_{d i}=k_{f i} / k_{r i}$ ), so the changes in Table 7 
suggest an increase in the partition coefficient by a factor of 5 to 6 (for the first site) when switching from $\mathrm{pH} 7.2$ to $\mathrm{pH}$ 6.7. This change is reasonable for uranium partitioning as a function of $\mathrm{pH}$ at constant $p \mathrm{CO}_{2}$ on various mineral surfaces (e.g., uranium sorption to ferrihydrite at $p \mathrm{CO}_{2}=0.01 \mathrm{~atm}$, Davis and Curtis, 2003, Fig. 5.1).

We note that the transition from uranium-bearing to uranium-free solutions frequently resulted in a short spike in uranium concentrations at the time of the transition. We attribute this to a pressure/flow transient during the syringe change-out that likely resulted in some uranium mobilization., possibly from the tubing surfaces rather than the geologic media. There was also a small $\mathrm{pH}$ spike that was observed during the transition (at $\sim 100 \mathrm{ml}$ in Figure 9), which could also have caused a spike in uranium concentrations.

Increases in $\mathrm{pH}$ late in the column experiments clearly promoted uranium desorption. It was interesting, however, that the best-fitting desorption rate constant for the first site was lower after the $\mathrm{pH}$ was raised from 6.7 to 7.2 than it was during the initial $\mathrm{pH} 7.2$ portion of the experiment, suggesting some adsorption/desorption hysteresis. Also, the increase to $\mathrm{pH} 8.8 \mathrm{did}$ not result in extremely rapid or complete desorption of the uranium, which might be expected based on the fact that no uranium adsorption was observed in either the batch or column experiments conducted at $\mathrm{pH}$ 8.8. These results suggest that uranium that adsorbed at lower $\mathrm{pHs}$ or that was exposed to lower pHs while adsorbed to the granodiorite surfaces was more resistant to desorption after the $\mathrm{pH}$ was increased than it would have been if the $\mathrm{pH}$ had always remained at the higher $\mathrm{pH}$. Mass recovery calculations indicated that the amount of uranium remaining in the columns after extended periods of flow at $\mathrm{pH} 8.8$ for the $75-150 \mu \mathrm{m}, 150-355 \mu \mathrm{m}$, and 355$500 \mu \mathrm{m}$ size fraction columns were $22 \%, 22 \%$, and $16 \%$, respectively. These recoveries cannot be unequivocally attributed to the geologic materials because of the observed interactions of 

increase in concentration that the model did not predict. When flow was re-established, it is very possible that the first water collected had artificially high uranium concentrations because of redissolution of precipitated uranium in the tubing. The model predicted that the long flow interruption would actually result in a decrease in uranium concentration rather than an increase, and the slight dip in uranium concentrations observed after the initial spike is consistent with this prediction. The two subsequent flow interruptions and the increase in the flow rate did not result in significant shifts in uranium concentrations, also consistent with model predictions. The reason for this behavior is that the equilibrium partitioning in the columns was shifted to greater uranium partitioning to the solids after the $\mathrm{pH}$ decrease. In effect, the release of uranium was dictated by a sharp increase in the ability of the granodiorite to adsorb uranium, and in particular, the ability of the sites with the fastest sorption/desorption kinetics in the column to adsorb uranium (i.e., the first site). The drop in $\mathrm{pH}$ effectively caused the first (fastest) site type to rapidly transition from being nearly completely loaded with uranium at $\mathrm{pH} 7.2$ to being significantly under-loaded at $\mathrm{pH}$ 6.7. The lower, steady concentrations in the long tail after the 
transition essentially reflect this new partitioning, rather than a true desorption rate. In other words, they reflect a desorption rate only of the most abundant and fastest site, not of the slower sites.

Changes in flow rates or flow interruptions of various durations can be useful for interrogating slow desorption kinetics, particularly when implemented well into the tail of a column breakthrough experiment. The magnitude of an increase in concentration after a flow interruption or after a decrease in flow rate can provide information on desorption kinetics, although it can also indicate an influence of diffusion and/or adsorption-desorption behavior in secondary porosity in the column (Liu et al., 2013, 2008). The magnitude of the concentration decrease after a flow rate increase can provide the same information. These generalizations hold true only if the contaminant is not effectively in equilibrium with the fastest sorption sites on the solids in the column. This was not strictly the case for uranium at $\mathrm{pH} 6.7$ in the columns because of the shift in equilibrium partitioning to favor stronger partitioning to all sites when the $\mathrm{pH}$ was dropped from 7.2 to 6.7. The lack of any significant increase or decrease in concentration after a flow interruption or flow rate change suggests that adsorption and desorption rates were approximately equal at the time of the flow transients (and there were no dual-porosity effects). The slight decrease in concentrations after the first long flow interruption (ignoring the spike that probably resulted from dry-out of the column tubing) indicates that adsorption rates were slightly greater than desorption rates at the time of this interruption, which reflects that there were still plenty of unoccupied sorption sites in the column at the lower $\mathrm{pH}$. The fact that concentrations did not change much with the flow interruptions and flow rate changes, particularly the late ones, also suggests that there was very little diffusive mass transfer between primary and secondary 
porosity in the system. Consequently, the model assumed only single-porosity transport behavior.

\subsection{Implications for large-scale reactive transport predictions}

Despite the shortcomings and lessons learned in our experiments, we believe that the small column procedure holds great promise for being able to interrogate the slow desorption rates that can be a significant source of uncertainty in large-scale performance assessment calculations. To illustrate the sensitivity of large-scale reactive transport predictions to slow desorption rates, Figure 12 shows the results of some large-scale predictive simulations using the pH 7.2 parameters determined for the largest granodiorite size fraction in the column experiments. These simulations were conducted using the same three-site model that was used to match the column data. It was assumed that there was a one-year groundwater travel time from the source to the point of compliance (not unusual for a fractured crystalline rock system). The uranium source was either a continuous input concentration (solid curves) or a 10-year constant-concentration pulse (dashed curves), with the input concentrations being the same as those used in the batch and column experiments $(6.5 \mu \mathrm{M})$. The black curves correspond to model predictions using the exact parameters given in Table 7 for the largest size fraction and the red curves correspond to model predictions using these same parameters except that the desorption rate constant of the third site was decreased by one order of magnitude. 


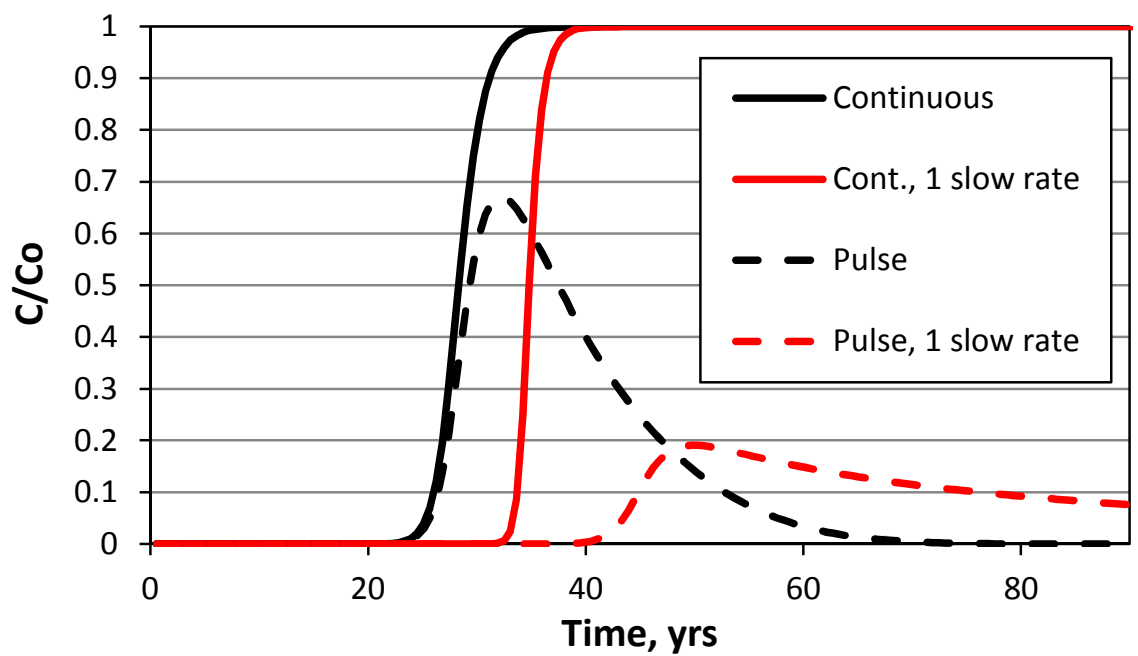

Figure 12. Large-scale model predictions for continuous and 10-year pulse inputs using reaction parameters for the three-site model (black curves) and for the three-site model with the desorption rate constant of the third site decreased by one order of magnitude (red curves). Groundwater travel time is one year.

These different desorption rate constants for the third site cannot be readily distinguished from the current column experiment data, and it would be very difficult to interrogate either of these rate constants in batch sorption/desorption experiments given the predominance of the first adsorption site. However, it should be possible to interrogate these rate constants and distinguish between them in more carefully-designed column experiments (i.e., experiments implementing the suggested improvements in section 4.5).

Figure 12 shows that for a continuous input, the arrival of uranium at the compliance point is delayed by about $30 \%$ ( $~ 8$ years) for the slower desorption rate constant (of the third site) relative to the faster desorption rate constant. The difference between the desorption rate constants is more striking in the case of the pulse input (dashed curves), where the delay in arrival time for the slower rate constant is about $70 \%$ ( $\sim 17$ years) relative to the faster desorption rate constant. In addition, the peak uranium concentration is over 3 times lower in the case of the slower desorption rate constant. The reason for the greater impact on the pulse input is that the 
small fraction of slow sites exerts a greater influence when the total inventory of uranium transporting through the system is smaller, as is the case for the 10-year pulse compared to the continuous input. With a continuous input, the slow sites fill up rather quickly after the leading edge of the "plume" passes by, which results in these sites no longer exerting much influence on transport. With a pulse input, a greater fraction of the slow sites remain unoccupied as the plume passes by, so these sites continue to have an effect on transport.

The slow sites can also have a greater impact on reactive transport when the source has a smaller concentration. Figure 13 shows the results of four continuous-input simulations, with two being identical to those of Figure 12, and two having an order-of-magnitude lower input concentration than was assumed in the simulations of Figure 12. It is apparent that (1) for the same rate constant, there is greater uranium attenuation at the lower input concentration, and (2) the difference between the curves associated with the slower and faster desorption rate constants is much greater at the lower input concentration. The explanation for these results is the same as for the pulse input versus the continuous input at the higher concentrationThe total inventory of

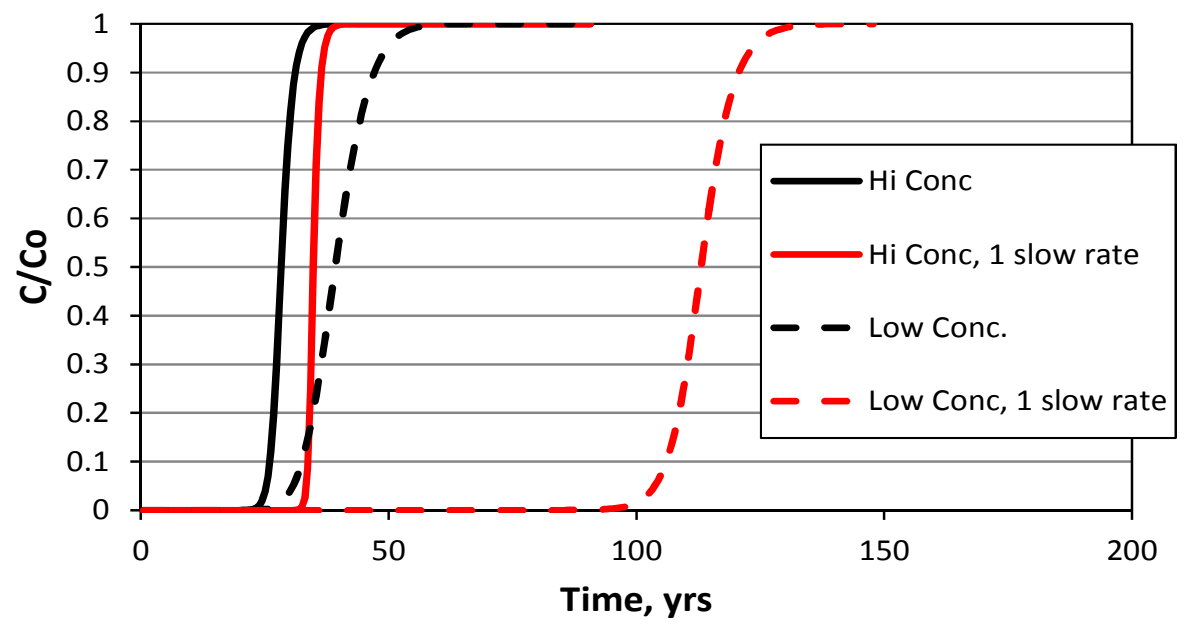

Figure 13. Large-scale model predictions for continuous inputs of two different concentrations using the reaction parameters for the three-site model and for the three-site model with the desorption rate constant of the third site decreased by one order of magnitude. Input concentrations are $6.5 \mathrm{mM}$ (hi) and $0.65 \mathrm{mM}$ (low). Groundwater travel time is one year. 
uranium is much smaller in the case of the lower input concentration, so the slow sites do not fill up as rapidly and exert a greater influence on reactive transport at the lower concentration.

These simulations illustrate how important even a relatively small number of sites having slow desorption rates can be for predictions of large-scale reactive transport. Our experimental method is intended to interrogate the rate constants of these relatively sparse slow sites, which are very difficult to interrogate using batch experimental methods. We recognize that the current set of experiments was not optimal for this interrogation; hence the suggested improvements of Section .5. However, among the positive attributes of our column experiments was the use of uranium concentrations approaching the solubility limit and the extended periods of time that uranium was injected into the columns at these concentrations. These strategies maximized the loading of uranium onto the granodiorite and increased the probability that significant amounts of uranium would adsorb to the slower sites that we were targeting for interrogation. The estimated loading of the uranium onto the granodiorite in the columns was in the range of 0.6 to $1.0 \mu \mathrm{M} / \mathrm{m}^{2}$, depending on the size fraction (higher loadings on larger size fractions), allowing for some uncertainty in the fraction adsorbed to granodiorite versus system components. These loadings are generally higher than in the batch experiments. In effect, this approach increased the desorption signal that could be observed from the slow sites after uranium concentrations were decreased.

\subsection{Integrating the method with other approaches for describing contaminant transport}

The multi-site, multi-rate reactive transport modeling approach that we used here is well suited to fitting the data from column experiments that are designed to interrogate slow adsorption/desorption sites. This method should be quite robust for developing large-scale reactive transport process models for contaminants exhibiting adsorption/desorption behavior 

the method should involve experiments conducted over the expected range of solution conditions to ensure rate constants can be determined as a function of these conditions. It is important to carefully control and measure the solution conditions in each experiment so that one is not misled by behavior that might be attributed to subtle changes in the conditions. We suspect that some of the minor upward and downward trends in uranium concentrations when the $\mathrm{pH}$ was held at 6.7 in our column experiments might have been caused by subtle changes in alkalinity, which we were not strictly controlling.

Davis and Curtis (2003) incorporated generic surface complexation reactions into their modeling approach and used a geochemical speciation model to deduce multiple uranium surface complexation reactions of varying strength (i.e., varying magnitudes of equilibrium constants) that were most likely to be responsible for the behavior they observed under numerous sets of solution conditions in batch experiments. This allowed them to develop a single model with a minimal number of adjustable parameters without accounting for specific uranium-mineral surface complexation reactions. This model could predict uranium adsorption over a relatively wide range of solution conditions. However, they were unable to obtain good constraints on rate constants from their batch experiments, and their forward predictions of column experiments using a local-equilibrium modeling approach (i.e., fast reaction kinetics relative to transport rates) did not match the tails in the column experiments very well. Our approach sacrifices some of the mechanistic basis of their approach to obtain better constraints on rate constants of 
relatively sparse sites, which, as we have shown (Section 4.3), can have a significant impact on large-scale transport predictions. There is no fundamental reason why we couldn't adopt an interpretive modeling approach for the column experiments that incorporates detailed geochemical speciation AND allows adsorption and desorption reactions to be described by rate expressions rather than equilibrium expressions. We believe that this is a reasonable next step in advancing our method and integrating it better with methods such as that used by Davis and Curtis (2003) and adopted/modified more recently by others (Liu et al., 2009, 2008) while keeping the model as simple as possible so that it can be readily incorporated into larger-scale risk assessment models.

The small size of the columns used in our experiments makes it possible to conduct numerous experiments, including duplicates, under different flow and geochemical conditions without great expense. However, column experiments are still fundamentally more complex to conduct than batch experiments, so it will always be possible to evaluate more solution variables for a fixed amount of resources using batch experiments. We believe a good approach is to balance the use of batch experiments to evaluate equilibrium partitioning and to constrain rapid adsorption and desorption rates with column experiments to interrogate the sparser, slower adsorption sites that have a significant impact on large-scale reactive transport predictions.

\subsection{Lessons learned and suggested improvements to the experimental method}

We consider the experiments and interpretations described in this paper to be an attempt at demonstrating an improved method for parameterizing reactive transport process models that can be used in risk assessments for predicting contaminant transport over long time and distance scales. As an initial attempt, there were a number of lessons learned and improvements that could be made in future applications of the method. First, it would be preferable to use 
experimental systems consisting of materials that have little or no interaction with the contaminant of interest, if possible. The interactions of uranium with the Tygon ${ }^{\circledR}$ tubing and other system components at the lower $\mathrm{pHs}$ in our experiments introduced uncertainty into the model interpretations and reactive transport parameter estimates. However, we showed that control experiments allowed these interactions to be reasonably well quantified so that they could be accounted for in the experiment interpretations (by correcting the injection functions). It is recommended that future applications of the small column method involve batch control experiments to screen for undesirable interactions and blank columns to allow any unavoidable interactions to be quantitatively accounted for.

A second improvement to the method would be to conduct experiments in which the solution conditions are held constant for much longer time periods when desorption is being observed. This would allow interrogation of slower desorption rate constants than those deduced in this set of experiments. It may be preferable to keep the solution conditions constant until the contaminant concentration drops to detection limits. This strategy would maximize the interrogation of slow desorption rates. Another approach would be to conduct batch adsorptiondesorption experiments with desorption starting after different periods of adsorption so that the influence of adsorption time on desorption kinetics can be investigated. These types of experiments would be ideal for evaluating so-called "bond-aging" effects (Kaplan and Serkiz, 2004).

When mass balance calculations indicate that a significant amount of contaminant is still adsorbed in the columns, the best approach may be to keep the solution conditions constant until contaminant concentrations approach detection limits and then change the solution conditions to promote additional desorption. 


\section{Conclusions}

The results of the column experiments highlight the extreme sensitivity of uranium adsorption and reactive transport behavior to solution $\mathrm{pH}$ and alkalinity at near-neutral $\mathrm{pH}$ (alkalinity via its dependence on $\mathrm{pH}$ under atmospheric conditions). This sensitivity is well known (Davis and Curtis, 2003; Waite et al., 1994) and is a result of the dependence of uranium solution speciation on $\mathrm{pH}$ and alkalinity, which results in dramatic shifts between positive, negative and neutrally charged uranium species over narrow ranges of solution chemistry. Adsorption is much stronger in almost any mineral system when there is a greater abundance of positively charged solution species (predominantly $\mathrm{UO}_{2}{ }^{2+}$ ) provided the $\mathrm{pH}$ is high enough that the mineral surfaces have a net negative surface charge. The granodiorite system is clearly no exception.

We conclude that at neutral $\mathrm{pH}$ and the natural alkalinity of the Grimsel ground water, uranium will be significantly retarded by adsorption in the Grimsel Test Site granodiorite system. At $\mathrm{pH} 7.2$, the effective uranium partition coefficient, or $K_{d}$ value, is at least 4 to $8 \mathrm{~mL} / \mathrm{g}$, and at 
$\mathrm{pH} 6.7$ it is 5 to 6 times larger. These values are considered lower limits because they do not account for the impact of slow sites, which were not optimally interrogated in our experiments. The calculations of the preceding section demonstrated how the effective $K_{d}$ values could be much larger over longer time and distance scales if slow sites are taken into account, particularly if uranium concentrations are lower than in our experiments.

At the natural $\mathrm{pH}$ of the Grimsel system, which is around 9.0, uranium retardation appears to be negligible under oxidizing conditions. However, our experiments did suggest that there is some potential for non-negligible retardation of uranium at $\mathrm{pH} 8.8$ based on the observation that the uranium that was adsorbed at lower pHs did not all rapidly desorb when the $\mathrm{pH}$ was raised to 8.8. Desorption $K_{d}$ values deduced from our experiments at $\mathrm{pH} 8.8$ were 0.3 to $0.5 \mathrm{~mL} / \mathrm{g}$ for the first and second adsorption sites, respectively, and about $20 \mathrm{~mL} / \mathrm{g}$ for a relatively sparse but much stronger/slower third site.

\section{Acknowledgments}

The authors would like to thank Doug Ware for his assistance with experimental setup, liquid scintillation counting protocols, sample analysis, and microphotograph imagery. Michael Cheshire and Hongwu Xu conducted the quantitative x-ray diffraction analyses of the Grimsel materials. Emily Kluk conducted the x-ray fluorescence analyses of the Grimsel materials. Cindy Dean provided the PHREEQC calculations reported in Table 4. We also thank Ingo Blechschmidt of the Swiss Nuclear Waste Cooperative, NAGRA, for providing the granodiorite and FFM materials. This work was supported by the U.S. DOE Nuclear Energy Office, Fuel Cycle R\&D Program, Used Fuel Disposition Campaign, which is administered by Sandia 
National Laboratories. The authors greatly appreciate the valuable comments provided by two anonymous reviewers.

\section{References}

Arnold, B.A., Reimus, P.W., James, S.C., 2011. Flow and Transport in Saturated Media: FY2011 Status Report. Prepared for U.S. Department of Energy Used Fuel Disposition Campaign, FCRD-USED-2011-000311, Sandia National Laboratories and Los Alamos National Laboratory.

Bates, E.A., Driscoll, M.J., Lester, R.K., and Arnold, B.W., 2014. Can deep boreholes solve America's nuclear waste problem? Energ. Policy 72, 186-189.

Crançon, P., Pili, E., Charlet, L., 2010. Uranium facilitated transport by water-dispersible colloids in field and soil columns. Sci. Total Environ. 408(9), 2118-2128.

Dai, Z., Wolfsberg, A., Reimus, P., Deng, H., Kwicklis, E., Ding, M., Ware, D., Ye, M., 2012. Identification of sorption processes and parameters for radionuclide transport in fractured rock. J. Hydrol. 414, 220-230.

Davis, J.A., Ochs, M., Olin, M., Payne, T.E., Tweed, C.J., 2005. NEA Sorption Project Phase IIInterpretation and Prediction of Radionuclide Sorption onto Substrates Relevant for Radioactive Waste Disposal Using Thermodynamic Sorption Models. Nuclear Energy Agency, Paris.

Davis, J.A., Meece, D.E., Kohler, M. Curtis, G.P., 2004. Approaches to surface complexation modeling of uranium(VI) adsorption on aquifer sediments. Geochim. Cosmochim. Acta 68(18), 3621-3641.

Davis, J.A., Curtis, G.P., 2003. Application of Surface Complexation Modeling to Describe Uranium(VI) Adsorption and Retardation at the Uranium Mill Tailings Site at Naturita, Colorado, NUREG/CR-6820, United States Geological Survey (for Nuclear Regulatory Commission), Menlo Park, CA.

Davis, J.A., 2001. "Surface Complexation Modeling of Uranium(VI) Adsorption on Natural Mineral Assemblages" U.S. Nuclear Regulatory Commission, NUREG/CR-6708.

Davis, J.A., Kent, D.B., 1990. Surface Complexation Modeling in Aqueous Geochemistry, Mineral-Water Interface Geochemistry, Reviews in Mineralogy Series, Mineralogical Society of America, Vol. 23, pp. 177-260.

Dean, C.A., 2010. Long-term desorption of uranium and neptunium in heterogeneous volcanic tuff materials, Ph.D. Dissertation, Chemical and Nuclear Engineering Department. University of New Mexico, Albuquerque, NM.

Dittrich, T.M., Gable, C.W., Karra, S., Makedonska, N., Painter, S.L., Reimus, P.. 2014. Describing uranium transport in a fractured crystalline rock using mini-column experiments. 
Crystalline and Crystalline International Disposal Activities. US DOE Used Fuel Disposition Report. FCRD-UFD-2013-000495. pp. 43-69.

Dittrich, T.M., Reimus, P.W.. 2013. Experimental evaluation of actinide transport in a fractured granodiorite. Proceedings of the 14th International High-Level Radioactive Waste Management Conference, American Nuclear Society, LaGrange Park, IL. pp. 473-480.

Doherty, J.E., 2010. Addendum to the PEST Manual, in: J.E. Doherty (Ed.). Watermark Numerical Computing, Brisbane, Australia, p. 131.

Doherty, J.E., 2009. Manual for PEST: Model Independent Parameter Estimation, in: J.E. Doherty (Ed.). Watermark Numerical Computing, Brisbane, Australia, p. 336.

Dong, W., Wan, J., 2014. Additive surface complexation modeling of uranium(VI) adsorption onto quartz-sand dominated sediments. Env. Sci. Tech. 48(12), 6569-6577.

Dong, W., Brooks, S., 2006. Determination of the formation constants of ternary complexes of uranyl and carbonate with alkaline earth metals $\left(\mathrm{Mg}^{2+}, \mathrm{Ca}^{2+}, \mathrm{Sr}^{2+}\right.$, and $\left.\mathrm{Ba}^{2+}\right)$ using anion exchange method. Env. Sci. Tech. 40(15), 4689-4695.

Driscoll, M.J., Lester, R.K., Jensen, K.G., Arnold, B.W., Swift, P.N., Brady, P.V., 2012. Technology and policy aspects of deep borehole nuclear waste disposal. Nucl. Technol. 180(1), 111-121.

Echevarria, G., Sheppard, M.I., Morel, J.L., 2001. Effect of pH on the sorption of uranium in soils. J. Env. Radioactivity 53(2), 257-264.

Geckeis, H., Schäfer, T., Hauser, W., Rabung, Th., Missana, T., Degueldre, C., M $\square$ ri, A., Eikenberg, J., Fierz, Th., Alexander W., 2004. Results of a colloid and radionuclide retention experiment (CCR) at the Grimsel Test Site (GTS), Switzerland - impact of reaction kinetics and speciation on radionuclide migration. Radiochim. Acta 92, 765-774.

Giammar, D. E., Hering, J. G., 2001. Time scale for sorption-desorption and surface precipitation of uranyl on Goethite. Env. Sci. Tech. 35(16), 3332-3337.

Good, N.E., Winget, G.D., Winter, W., Connolly, T.N., Izawa, S., Singh, R. M.M., 1966. Hydrogen ion buffers for biological research. Biochemistry 5(2), 467-477.

Huber, F., Kunze, P., Geckeis, H., Schäfer, T., 2011. Sorption reversibility kinetics in a ternary system radionuclide - bentonite colloids/nanoparticles - granite fracture filling material. Appl. Geochem. 26, 2226-2237.

Ilton, E.S., Wang, Z., Boily, J., Qafoku, O., Rosso, K.M., Smith, S.C., 2012. The effect of pH and time on the extractability and speciation of uranium(VI) sorbed to $\mathrm{SiO}_{2}$. Env. Sci. Tech. 46(12), 6604-6611.

Johnson, J., 2010. llnl.dat 4023 2010-02-09. Data from 'thermo.com.V8.R6.230' prepared by Jim Johnson at Lawrence Livermore National Laboratory, in Geochemist's Workbench format. Converted to PHREEQC format by Greg Anderson with help from David Parkhurst. 

of $\mathrm{U}(\mathrm{VI})$ onto Opalinus clay: Effects of $\mathrm{pH}$ and humic acid. Appl. Geochem. 36, 104-117.

Kaplan, D.I., Serkiz, S.M., 2004. Quantification of thorium and uranium sorption to contaminated sediments. J. Radioanal. Nucl. Chem. 248(3), 529-535.

Kohler, M., Davis, J.A., 2001. "Uranium(VI) Adsorption on Crushed Quartz in $\mathrm{NaNO}_{3} / \mathrm{HCO}_{3}$ Systems," Surface Complexation Modeling of Uranium(VI) Adsorption on Natural Mineral Assemblages, U.S. Nuclear Regulatory Commission, NUREG/CR-6708, 214, 2001.

Kohler, M., Curtis, G.P., Kent, D.B., Davis, J.A., 1996. Experimental investigation and modeling of uranium(VI) transport under variable chemical conditions. Water Resour. Res. 32(12) 3539-3551.

Liu, C.X., Shang, J.Y., Kerisit, S., Zachara, J. M., Zhu, W.H., 2013. Scale-dependent rates of uranyl surface complexation reaction in sediments. Geochim Cosmochim. Acta 105, 326341.

Liu, C.X., Shi, Z.Q., Zachara, J.M., 2009. Kinetics of uranium(VI) desorption from contaminated sediments: effect of geochemical conditions and model evaluation. Env. Sci. Tech. 43(17), 6560-6566.

Liu, C., Zachara, J. M., Qafoku, N. P., Wang, Z., 2008. Scale-dependent desorption of uranium from contaminated subsurface sediments. Water Resour. Res. 44(8),

Missana, T., Garcia-Gutierrez, M., Alonso, U., 2004. Kinetics and irreversibility of cesium and uranium sorption onto bentonite colloids in a deep granitic environment. Appl. Clay Sci. 26, 137-150.

Morel F.M.M., Hering, J.G., 1993. Principles and Applications of Aquatic Chemistry. WileyInterscience, New York.

Möri, A. (Ed.), 2004. The CRR final project report series 1: Description of the Field Phase Methodologies and Raw Data. Nagra Technical Report NTB 03-01. Nagra, Wettingen, Switzerland.

Möri, A., Alexander, W., Geckeis, H., Hauser, W., Schäfer, T., Eikenberg, J., Fierz, T., Degueldre, C., Missana, T., 2003. The colloid and radionuclide experiment at the Grimsel Test Site: influence of bentonite colloids on radionuclide migration in a fractured rock. Colloids Surf. A - Physicochem. Eng. Aspects 217(1), 33-47.

Nebelung, C., Brendler, V., 2010. U(VI) sorption on granite: predictions and experiments. Radiochim. Acta 98, 621-625.

Parkhurst, D. L., Appelo, C. A. J., 2013. PHREEQC (Version 3.0.4) - A computer program for speciation, batch speciation, one-dimensional transport, and inverse geochemical calculations, U.S. Geological Survey Techniques and Methods, Book 6, Chapter A43, p. 497, http://pubs.usgs.gov/tm/06/a43/. 
Payne, T.E., Brendler, V., Ochs, M., Baeyens, B., Brown, P.L., Davis, J.A., Ekberg, C., Kulik, D.A., Lutzenkirchen, J., Missana, T., Tachi, Y., Van Loon, L.R., Altmann, S., 2013. Environ. Modell. Softw. 42, 143-156.

Reimus, P.W.. Dittrich, T.M. 2013. An experimental methodology for improving radionuclide transport process models using uranium and Grimsel granodiorite as a case study. Experimental and Modeling Investigation of Radionuclide Interaction and Transport in Representative Geologic Media. US DOE Used Fuel Disposition Report. FCRD-UFD-2013000314. pp. 44-76.

Schwartz, M.O., 2012. Modelling radionuclide transport in large fractured-media systems: the example of Forsmark, Sweden. Hydrogeol. J. 20(4), 673-687.

Shang, J.Y., Liu, C.X., Wang, Z.M., Zachara, J., 2014. Long-term kinetics of uranyl desorption from sediments under advective conditions. Water Resour. Res. 50(2), 855-870.

Shang, J.Y., Liu, C.X., Wang, Z.M., Zachara, J., 2011. Effect of grain size on uranium(VI) surface complexation kinetics and adsorption additivity. Env. Sci. Tech. 45(14), 6025-6031.

Sheppard, S.C., Sheppard, M.I., Tait, J.C., Sanipelli, B.L., 2006. Revision and meta-analysis of selected biosphere parameter values for chlorine, iodine, neptunium, radium, radon and uranium. J. Environ. Radioact. 89, 115-137.

Soler, J.M., Vuorio, M., and Hautojarvi, A., 2011. Reactive transport modeling of the interaction between water and a cementitious grout in a fractured rock. Application to ONKALO (Finland). Appl. Geochem. 26(7), 1115-1129.

Vandenhove, H., Gil-Garcia, C., Rigol, A., Vidal, M., 2009. New best estimates for radionuclide solid-liquid distribution coefficients in soils. Part 2. Naturally occurring radionuclides. $J$. Environ. Radioactiv. 100(9), 697-703.

Waite, T.D., Davis, J.A., Fenton, B.R., Payne, T.E., 2000. Approaches to modelling uranium(VI) adsorption on natural mineral assemblages. Radiochim. Acta 88, 687-693.

Waite, T.D., Davis, J.A., Payne, T.E., Waychunas, G.A., Xu, N., 1994. Uranium(VI) adsorption to ferrihydrite - Application of a surface complexation model. Geochim Cosmochim. Acta, 58(4), 5465-5478. 